\title{
Nuclear Receptors as Multiple Regulators of NLRP3 Inflammasome Function
}

OPEN ACCESS

Edited by:

Kuo-Feng Hua,

National llan University, Taiwan

Reviewed by:

Benoit Pourcet,

Université de Lille, France

Raphaela Goldbach-Mansky,

National Institutes of Health (NIH),

United States

*Correspondence:

Szilvia Benkó

benkosz@med.unideb.hu

Specialty section:

This article was submitted to Inflammation,

a section of the journal

Frontiers in Immunology

Received: 17 November 2020 Accepted: 08 February 2021

Published: 26 February 2021

Citation:

Alatshan A and Benkő S (2021)

Nuclear Receptors as Multiple Regulators of NLRP3 Inflammasome

Function. Front. Immunol. 12:630569.

doi: 10.3389/fimmu.2021.630569

\begin{abstract}
Ahmad Alatshan ${ }^{1,2}$ and Szilvia Benkö ${ }^{1,2 *}$
${ }^{1}$ Departments of Physiology, Faculty of Medicine, University of Debrecen, Debrecen, Hungary, ${ }^{2}$ Doctoral School of Molecular Cellular and Immune Biology, Faculty of Medicine, University of Debrecen, Debrecen, Hungary
\end{abstract}

Nuclear receptors are important bridges between lipid signaling molecules and transcription responses. Beside their role in several developmental and physiological processes, many of these receptors have been shown to regulate and determine the fate of immune cells, and the outcome of immune responses under physiological and pathological conditions. While NLRP3 inflammasome is assumed as key regulator for innate and adaptive immune responses, and has been associated with various pathological events, the precise impact of the nuclear receptors on the function of inflammasome is hardly investigated. A wide variety of factors and conditions have been identified as modulators of NLRP3 inflammasome activation, and at the same time, many of the nuclear receptors are known to regulate, and interact with these factors, including cellular metabolism and various signaling pathways. Nuclear receptors are in the focus of many researches, as these receptors are easy to manipulate by lipid soluble molecules. Importantly, nuclear receptors mediate regulatory mechanisms at multiple levels: not only at transcription level, but also in the cytosol via non-genomic effects. Their importance is also reflected by the numerous approved drugs that have been developed in the past decade to specifically target nuclear receptors subtypes. Researches aiming to delineate mechanisms that regulate NLRP3 inflammasome activation draw a wide range of attention due to their unquestionable importance in infectious and sterile inflammatory conditions. In this review, we provide an overview of current reports and knowledge about NLRP3 inflammasome regulation from the perspective of nuclear receptors, in order to bring new insight to the potentially therapeutic aspect in targeting NLRP3 inflammasome and NLRP3 inflammasome-associated diseases.

Keywords: inflammasome, NLRP3, IL-1 $1 \beta$, signaling, PPAR, LXR, PXR, metabolism

\section{INTRODUCTION}

\section{The Nuclear Receptors}

Nuclear receptors (NRs) are ligand-dependent transcription factors that regulate numerous physiological mechanisms, including development, differentiation, metabolism and immune functions $(1,2)$. Generally, nuclear receptors are activated by endogenous or exogenous small lipophilic molecules to control the transcription of a complex network of gene sets for a targeted function (3). In addition to their role as transactivators or transrepressors (genetic level), several 
NRs may initiate a processes of histone modifications and chromatin remodeling (epigenetic level). Furthermore, increasing number of evidence shows that they are involved in various intracellular, non-genomic functions; such as the modulation of signal transduction pathways and cell membrane receptors activity $(4,5)$.

Most nuclear receptors share the same domain structure. Some of these domains are highly conserved; such as the DNA binding domain (DBD) that contains a zinc-finger motif and mediates the interaction of the protein to the DNA, and the ligand binding domain (LBD) that binds the receptor specific agonist or antagonist molecules. DBD and LBD are connected through the hinge in the middle region of the receptor that provides a structural flexibility. In addition, the N-terminal domain (NTD) contains the activator function-1 (AF-1) (ligand-independent) motif, while the LBD contains the activator function-2 (AF2) (ligand-dependent) motif (6-8) (Figure 1). The hydrophobic pocket within $\mathrm{LBD}$ is arranged in a way that gives the pocket a unique character to accommodate specifically the cognate ligands. However, some nuclear receptors have a flexible pocket that binds structurally diverse ligands in various orientations, while others can adopt an active state even in the absence of the ligands $(9,10)$.

These domains can also be targeted by various posttranslational modifications that modulate the nuclear receptor's function (11). The binding of the ligand induces conformational changes of the receptor, leading to the recruitment of a complex network of relevant regulatory proteins to complete gene expression activation or inhibition (8). As nuclear receptors can modulate chromatin accessibility, they have the ability to alter the binding of the transcription machinery (6). Nuclear receptors may function as monomers, form a complex of homodimers, or heterodimerize with other nuclear receptors.

The most common receptors which act as a heterodimerization partner with other nuclear receptors are the retinoid $\mathrm{X}$ receptors (RXRs) (12, 13) (Figure 2). Depending on the dimerization partner, RXR heterodimers are categorized as permissive and non-permissive dimers. In permissive heterodimers (e.g., PPAR/RXR and LXR/RXR), ligand binding to either partner can mediate their activities. While in non-permissive heterodimers (e.g., VDR/RXR and

Abbreviations: 1,25- $\mathrm{D}_{3}, 1,25$-dihydroxyvitamin $\mathrm{D}_{3}$; MPTP, 1- methyl-4-phenyl1,2, 3, 6-tetrahydropyridine; AKR1B7, Aldo-keto reductase family 1, member B7; ASC, Apoptosis-associated speck-like protein; ATRA, All-Trans Retinoic Acid; BMDMs, Bone marrow-derived macrophages; CHOP, C/EBP homologous protein; CAR, Constitutive androstane receptor; DAMPs, Damage-associated molecular patterns; ER, Endoplasmic reticulum; FXR, Farnesoid X receptor; GPBAR 1 TGR5G, protein-coupled bile acid receptor 1; HAMPs, Homeostasisaltering molecular processes; LXR, Liver X receptor; BRCC36, Lys-63-specific deubiquitinase; mtROS, Mitochondrial reactive oxygen species; NLRs, NODlike receptors; NKC1, Non-catalytic region of tyrosine kinase adaptor protein 1; NAFLD, Nonalcoholic fatty liver disease; PD, Parkinson's disease; PRRs, Pattern recognition receptors; PPARs, peroxisome proliferator-activated receptors; PPE, Porcine pancreas elastase; PKC, Protein kinase C; RAR, Retinoic acid receptor; RXR, Retinoid X receptor; ROR, Retinoic acid receptor-related orphan receptor; PERK, RNA-like endoplasmic reticulum kinase; SREBF1, Sterol regulatory element-binding transcription factor 1; SHP, Small heterodimer partner, NR0B2; TLRs, Toll-like receptors; VDR, Vitamin D Receptor.
$\mathrm{RAR} / \mathrm{RXR}$ ), the heterodimer remains silent if only RXR is bound, hence, ligand binding to the partners of RXR is a prerequisite for activation $(14,15)$. While permissive heterodimers seem to be lipid sensors that are regulated by many metabolic pathways (PPAR, LXR), non-permissive ones most likely respond to the classical endocrine steroid (ER) and non-steroid (RAR) factors (16). The crosstalk between nuclear receptors through typical (with RXR as a partner) and atypical (with other nuclear receptors) heterodimerization, as well as the alternative splicing of these receptors, poses a challenge to understand nuclear receptors-mediated gene regulation, and explains the variability in drug responses $(17,18)$.

\section{Inflammasomes}

Innate immune functions depend on pattern recognition receptors (PRRs) that recognize pathogen-associated molecular patterns (PAMPs), damage-associated molecular patterns (DAMPs) or homeostasis-altering molecular processes (HAMPs) $(19,20)$. Based on their localization, PRRs are classified to membrane-bound receptors [such as Toll-like receptors (TLRs), C-type lectin receptors (CLR)] and cytoplasmic receptors [nucleotide-binding domain leucine-rich repeat receptors (NLRs), retinoic acid-inducible gene-I (RIGI)-like receptors (RLRs), absent in melanoma (AIM)-like receptors (ALRs) and proteins-containing tripartite motif (TRIM)] (20-22).

Among the cytoplasmic PRRs, NLRP1, NLRP3, NLRC4, AIM2, and Pyrin have been thoroughly studied and identified as initiators of inflammasome multiprotein complex formation. Although other NLRs; such as NLRP6, NLRP7, NLRP9, and NLRP12 have also been shown capable to form inflammasomes, they need further characterization in order to better understand the conditions of their activation $(22,23)$.

Generally, NLRs are organized in a tripartite structure: the $\mathrm{N}$-terminal effector domain (pyrin (PYD) for NLRPs; caspaserecruitment domain (CARD) for NLRCs) required for signal transduction, the central NACHT domain (contains NBD) mediates self-oligomerization, and the C-terminal leucine-rich repeats (LRRs) involved in ligand detection $(24,25)$. In most cases. activation of the NLR triggers a rapid oligomerization process, leading to the recruitment and binding of the inactive pro-caspase-1 enzyme, either directly (NLRC4 inflammasome) or via the ASC adaptor protein (NLRP3 inflammasomes) $(22,26)$. Eventually, the autocatalytic activation of caspase1 leads to the processing of GSDMD, pro-IL-1 $\beta$ and pro-IL18 , to induce pore formation and facilitate inflammation or pyroptosis $(27,28)$.

Depending on the sensor protein of the inflammasome, different types of inflammasomes are activated by different stimuli, for example, NLRC4 recognizes flagellin, NLRP1 recognizes anthrax lethal toxin, and AIM2 is activated by dsDNA (29). However, the triggering stimuli for several inflammasome forming NLRs (such as NLRP2, NLRP6) have not yet been identified. Importantly, while NLRP3 inflammasome is probably the most studied and best characterized inflammasome complex, the direct activator of NLRP3 is still unknown. 


\section{NTD \\ DBD hinge \\ LBD

$\mathrm{H}_{2} \mathrm{~N}-\mathrm{AF}-1 \quad \mathrm{AF}-2-\mathrm{COOH}$

FIGURE 1 | Representation of the domains structure of the nuclear receptors. LBD, Ligand binding domain; DBD, DNA binding domain; AF-1, activator function-1; AF-2, activator function-2; NTD, N-terminal domain.

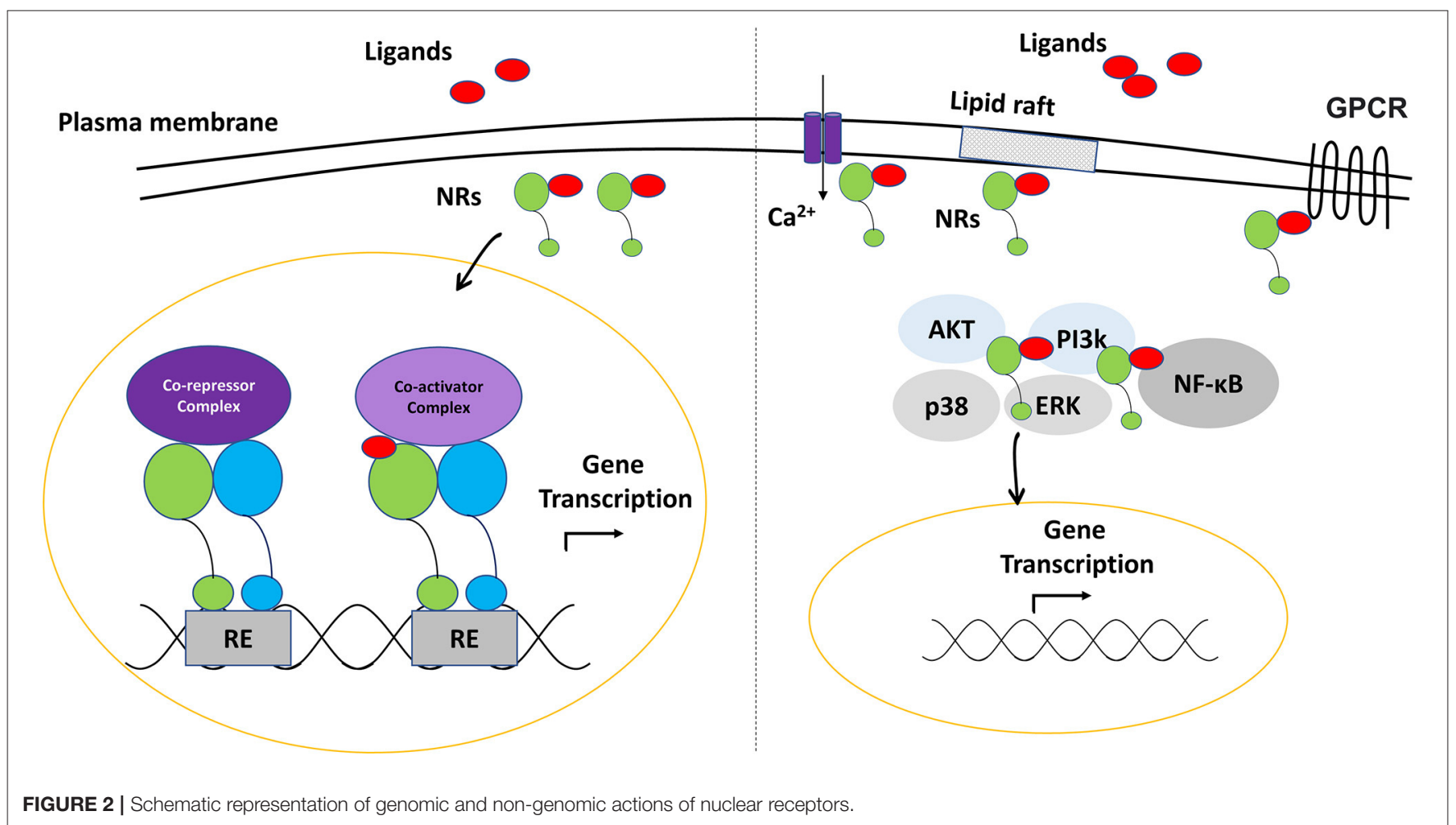

\section{NLRP3 Inflammasome}

The assembly of NLRP3 inflammasome mostly requires two events; priming and activation. The priming signal of NLRP3 inflammasome is mostly initiated by TLRs and triggers transcriptional induction of NLRP3 and IL1- $\beta$ genes via various signaling pathways including NF- $\mathrm{B}$ and MAPKs (JNK, p38, and ERK). Beside transcriptional regulation, priming-induced signaling is also involved in post-translational modifications (phosphorylation, SUMOylation, ubiquitination) that license the inflammasome components (NLRP3 and ASC) for activation (30-32).

The activation step of NLRP3 inflammasome facilitates NEK7 binding, and triggers the assembly of the multiprotein complex. Highly developed modern technologies such as cryo-EM, enabled a detailed structural and mechanistic understanding of NLRP3 inflammasome activation and signaling. It was proven that both PYD and CARD domains are able to form filaments through homotypic interaction. In the absence of a ligand, NLRs are characterized by an autoinhibited conformation, as the LRR folds back to the NBD, resulting in a closed conformation. Sensing of an activator induces a conformational change that leads to the oligomerization of the NLRP3, in a self-propagation process.
Thereafter, it recruits ASC through PYD-PYD interaction, and induces the helical ASC filament formation that assembles into large ASC specks, acting as a platform for pro-caspase-1 binding $(33,34)$.

As a result of intensive studies, a wide range of stimuli and stress signals have been identified for NLRP3 inflammasome activation, many of them are associated with the disturbance of cellular homeostasis or organelle dysfunction. For example, ion fluxes including $\mathrm{K}^{+}$or $\mathrm{Cl}^{-}$efflux, $\mathrm{Na} 2+$ influx or elevation of cytosolic $\mathrm{Ca}^{2+}$ are required to promote NLRP3 inflammasome assembly and formation (35). Crystals-induced lysosomal destabilization (following engulfment of cholesterol, MSU, $\beta$ amyloid) that leads to the cytosolic release of cathepsins and $\mathrm{Ca}^{2+}$ results in NLRP3 inflammasome activation $(36,37)$. Also ROS production following ER stress due to the accumulation of unfolded proteins (38); changes in metabolites and enzymes related to mitochondria function (succinate, itaconate, ATP) (39) or mitochondrial dysfunction (mtROS, oxidized mtDNA, cardiolipin) are proved to be inducers of NLRP3 activation (40). Importantly, mitochondria-associated membranes (MAMs) serve as platform for the NLRP3 inflammasome assembly (36, $41,42)$. Indeed, dysregulation of the NLRP3 inflammasome 
has been linked, and associated with severe diseases, including autoimmune, cardiovascular, neurodegenerative diseases, as well as allergy and cancer, conditions which required careful therapeutic intervention to downregulate the inflammasome network (43-45).

\section{Nuclear Receptors at the Crossroad of Metabolism and Inflammatory Responses}

A growing body of evidence show that nuclear receptors may intervene in responses through various mechanisms. Depending on the microenvironment, immune cells may undergo a wide range of polarization states via transcriptional (re)programming, which in part is regulated by nuclear receptors. The role of several nuclear receptors in the polarization and function of myeloid linage cells has been studied extensity $(46,47)$. For example, PPAR $\gamma$ or LXR activity is assumed as a hallmark of alternative or M2 macrophage polarization $(46,48)$. Conversely, under inflammatory conditions, macrophages tend to downregulate $\operatorname{PPAR} \gamma$ and its target genes, which diminish the lipid sensing function of these cells (49). However, PPAR $\gamma$ is required during the resolution phase of inflammatory response, and loss of PPAR $\gamma$ is associated with sustained immune response $(50,51)$.

For proper effector responses, immune cells adopt specific metabolic pathways, where nuclear receptors emerge as key links to fine-tune the immunometabolic effector functions of these cells. Indeed, several nuclear receptors, including FXR, PPARs, LXRs, or PXR, are grouped as metabolic receptors, as they coordinate a network of different metabolic pathways to generally maintain the systemic metabolic homeostasis $(3,52)$. Recently, active attempts were made to target immunometabolism as an approach to tackle inflammatory disorders (53), and nuclear receptors may function as potential therapeutic modulators at the crossroad of this approach.

Importantly, activation of the NLRP3 inflammasome in THP1 macrophage was associated with up-regulation of nuclear receptors, suggesting a negative feedback loop promoting resolution of inflammation (54). Consistently, a data mining study showed a strong association between inflammasome and nuclear receptors function, and that inflammasome pathways play a central role in the regulation and expression of nuclear receptors. This study categorized most of the nuclear receptors as sensors or receptors of homeostasis-altering molecular processes (HAMPs). It is a recently introduced expression that refers to alterations in cellular mechanisms and pathways that reflects cellular dysfunction and the loss of cellular homeostasis; consequently, HAMPs may modulate inflammatory responses and associate with several metabolic and immune dysfunction (55).

In response to stress signals, cells initiate a multifaceted program that integrates several highly regulated pivotal processes; including autophagy and inflammatory response (56). Autophagy is a crucial intracellular recycling process that is activated by various types of cellular stress, including protein aggregates, nutrient deprivation, hypoxia, damaged organelles and intracellular pathogens, in order to maintain cellular homeostasis and provide energy source or building molecule blocks for the cell (57). Beside macrophage polarization, several members of nuclear receptors are involved in autophagymediated defense at both transcriptional, and post-translational levels, [reviewed in (58)]. In addition, it has been reported that PPAR $\alpha$ and FXR regulate autophagy through a complementary transcription of autophagy genes under various nutrition status (59).

Autophagy and inflammasome; as a major inflammatory pathway, are tightly coupled events. Autophagy negatively regulates inflammasome function through several mechanisms, including the removal of endogenous inflammasome activators (DAMPs) or the inflammasome components. However, depending on the conditions, activation of the inflammasome and caspase-1 were found to modulate autophagy, either negatively or positively by various mechanisms $(60,61)$. Although, nuclear receptor function is associated with autophagy regulation, further experimental data are needed to elucidate the role of nuclear receptors in the crosstalk between autophagy and inflammasome function.

In addition to their role in the transcriptional regulation, nuclear receptors also possess non-genomic activity through the modulation of diverse basic cellular mechanisms, including Gprotein signaling, calcium flux, cyclic nucleotide (cAMP and cGMP) or nitric oxide production, and other signal transductions such as a variety of kinase pathways (4). All of which were described to mediate a variety of inflammatory responses, including inflammasome activation/function. Other factors; such as localization of the nuclear receptors in various cellular organelles, increase their potential to develop selective nongenomic activities characteristic to specialized cell types and tissues $(4,62)$. For example, several nuclear receptors (ER, TR RXR $\alpha$, RAR, Nur77/TR3 and PPAR $\beta$ and $-\gamma$ ) were reported to localize in the mitochondria, and become engaged with the mitochondrial transcription, this way, they coordinate the expression of genes encoding for enzymes involved in oxidative phosphorylation (OXPHOS) (63). Importantly, enzymes and products of mitochondrial TCA cycle or OXPHOS have already been recognized as important modulators of NLRP3 inflammasome function.

\section{Nuclear Receptors and NLRP3 Inflammasomes}

Recent studies categorized many of the nuclear receptors as sensors of cellular imbalance and dysfunction. Similarly, NLRP3 inflammasome may be activated by a large spectrum of molecules that are associated with cellular stress and altered metabolism. Data suggest that nuclear receptors are involved in a wide spectrum of cellular processes, and they can regulate inflammasome priming or activation through genomic and nongenomic effects.

Indeed, NLRP3 inflammasome activation may be triggered by lipid metabolites, that are also recognized as ligands by various NRs. For example, the cholesterol and its derivatives [oxysterol $(25 \mathrm{HC})]$ are natural ligand for LXR and FXR (64); various fatty acids including saturated fatty acids [palmitic acid (C15:0), stearic acid $(\mathrm{C} 18: 0)](65,66)$, mono-unsaturated fatty acids [oleic 
acid (C18:1)], or polyunsaturated fatty acid [linoleic acid (C18:2)] (67), omega-3 PUFAs [like eicosapentaenoic acid (EPA) and docosahexaenoic acid (DHA)] (68) are recognized by PPARs. Furthermore, enzymes and transporters of lipid metabolism pathways (including synthesis, degradation, or oxidation) that are regulated by various NRs, have also been associated to NLRP3 inflammasome activity as positive or negative regulators (69, 70). Such as fatty acid synthase (FASN) expression is regulated by LXR $\alpha$ (71); while fatty acid oxidation enzymes, NOX4 and carnitine palmitoyltransferase $1 \mathrm{~A}(\mathrm{CPT} 1 \mathrm{~A})$, by $\operatorname{PPAR} \gamma(72,73)$ and PPAR $\alpha$ (74), respectively. Expression of CD36 scavenger receptor, that transports cholesterol containing oxLDL to MFs, are regulated by PPAR $\gamma$ (75), while that of the ABCA1/ABCG1, that mediates cholesterol efflux, is regulated by $\operatorname{LXR}(76,77)$. The detailed mechanism of their actions on NLRP3 inflammasome has recently been described in excellent reviews (39, 7880). In the following section, we highlight known regulatory roles and mechanisms that nuclear receptors exert on NLRP3 inflammasome (Table 1).

\section{Retinoid X Receptor (RXR)}

RXRs are involved in the transcriptional programs of many biological processes, including cell differentiation, immune response, as well as lipid- and glucose metabolism. The importance of RXRs; as master nuclear receptors, are derived from their ability to play a unique role as obligate heterodimerizing partners of many other nuclear receptors (110). In fact, there is different affinity and competition between RXR partners to form heterodimers with RXR (111). In addition to its role as transcription factor in the nucleus, activation of RXR may induce its translocation into the mitochondria, in order to enhance the transcription of mitochondrial genes (such as COX-1) (112).

In mouse and human myeloid cells, RXRs have multifaceted functions, including polarization, uptake of apoptotic cells, inflammatory gene repression, cholesterol uptake and lipid processing [extensively reviewed in (113)]. For example, RXR is linked to IL-4-induced alternative polarization of macrophages, via modulating the phenotypic properties of this macrophage in gene-specific manner (114). During the years, many RXRspecific synthetic ligands and RXR-deficient mice were generated to avoid heterodimerization issues; which is regarded as a drawback in RXR-targeted therapeutic approaches. Currently, it seems that partial agonists for RXR with submaximal response could be an approach to avoid prolonged activation and side-effect (115).

Unfortunately, little is known about the exact role of RXRs in inflammasome regulation, as most studies focus on their dominant partners, particularly in permissive dimers. Interestingly however, one report suggested that NLRP3 inflammasome activation may regulate RXRs function (Figure 3). In ovalbumin-induced mice model of eosinophilic asthma, NLRP3 inflammasome activation was required for the induction of allergic response (116). They showed that NLRP3 specific inhibitor MCC950 significantly reduced both RXR expression and apoptosis in primary airway epithelial cells (pAECs), however, inhibition of apoptosis was reversed by the
RXR agonist adapalene. Although an NLRP3-RXR axis was suggested as important regulatory role for apoptosis, further studies are required to delineate the mechanism, and find direct association between NLRP3 and RXR.

\section{Small Heterodimer Partner (SHP)}

The orphan SHP is a unique nuclear receptor that lacks DBD. Though it has a classical LBD that contains a liganddependent transactivation domain (AF2), there are two NR-boxes within its NTD that mediate binding of other proteins. Interestingly, the SHP interacting proteins are mainly nuclear receptors (such as FXR, ER, LXR, PXR, RAR, CAR, and PPAR) or other transcription factors (such as BMAL1, c-Jun, SREBP-1c, FOXO1, p65, and USF1), and dimerization with SHP usually leads to transcriptional repression of their target gene (117). These interactions regulate complex networks of metabolism, hemostasis and immune responses $(52,117,118)$.

While the liver expresses SHP at a highest level, it is also expressed in various other tissues (such as, heart, adipose and intestinal tissues) in both human and mouse (119). In human, a number of mutations and single nucleotide polymorphism (SNP) were found to affect the function of SHP (117). The expression of SHP is transcriptionally regulated by ligated FXR, in order to regulate the biosynthesis of bile acids and cholesterol (52). SHP was shown to modulate TLR activation through interaction with downstream signaling NFKB and TRAF6, resulting in the attenuation of proinflammatory response (120).

In BMDMs, loss of SHP was shown to be associated with excessive pathologic responses, mediated by NLRP3 inflammasome activation. Though SHP did not affect the priming signal of NLRP3 inflammasome, it had the ability to compete with ASC for NLRP3 binding following treatment with various NLRP activators (ATP, MSU, nigericin), hence, it negatively regulated the activation and assembly of NLRP3 inflammasome (Figure 3). In addition, SHP directly associated with NLRP3, ASC, TXNIP and MAVS on mitochondrial membrane, in order to help mitochondrial translocation of NLRP3 inflammasome as well as to regulate mitochondrial homeostasis (103).

In pancreatic acinar cells however, thapsigargin treatment upregulated SHP expression that in turn, stabilized the spliced isoform of X-box-binding protein 1 (XBP1s) transcription factor, a key mediator of ER stress response (121). As ER and ER stress play a critical role in inflammasome activation by several mechanisms (such as ROS production) (43), this observation would predict the role of SHP as a facilitator of inflammasome function. In notion with this hypothesis, it was recently reported that XBP1s bound to the promoter region of NLRP3, and loss of XBP1 in renal ischemia/reperfusion- mediated injury was associated with a decrease in NLRP3-mediated caspase-1 activation (122). It seems that XBP1s' function is more likely to be tissue-specific, and depends on the testing conditions. In this context, SHP could be a potential target to modulate inflammasome function either directly, or via the regulation of XPB1s. 
TABLE 1 | Summary of nuclear receptors and their ligands involved in the NLRP3 inflammasome regulation (arranged in alphabetical order).

\begin{tabular}{|c|c|c|c|c|c|c|}
\hline NR & Mechanism & Effect & Cell type & Possible therapeutic & Used ligand & References \\
\hline FXR (NR1H4) & $\begin{array}{l}\text { Interacts with NLRP3 inflammasome } \\
\text { components and prevents their assembly, } \\
\text { in ligand dependent manner }\end{array}$ & $\begin{array}{l}\downarrow N L R P 3 \\
\text { inflammasome }\end{array}$ & $\begin{array}{l}\text { Peritoneal macrophage, Raw } 246.7 \\
\text { Sepsis-associated cholestasis mouse } \\
\text { model, FXR KO, FXR overexpression } \\
\text { in THP-1 }\end{array}$ & $\begin{array}{l}\text { Protects mice from septic shock } \\
\text { under cholestasis condition }\end{array}$ & GW-4064, DCA, CDCA, OCA & (81) \\
\hline FXR (NR1H4) & $\begin{array}{l}\text { Inhibits ER stress, attenuation of } \\
\text { CHOP-dependent NLRP3 overexpression } \\
\text { and inhibition of PERK activation }\end{array}$ & $\begin{array}{l}\downarrow N L R P 3 \\
\text { inflammasome }\end{array}$ & $\begin{array}{l}\text { Mouse primary hepatocytes, AML12 cell } \\
\text { line, FXR KO mouse }\end{array}$ & $\begin{array}{l}\text { Inhibits ER stress, ameliorates } \\
\text { hepatocyte death and liver injury }\end{array}$ & $\begin{array}{l}\text { GW4064, chenodeoxycholic } \\
\text { acid (CDCA) }\end{array}$ & (82) \\
\hline FXR (NR1H4) & $\begin{array}{l}\text { Inhibits oligomerization and ubiquitination } \\
\text { of ASC }\end{array}$ & $\begin{array}{l}\downarrow \text { NLRP3 } \\
\text { inflammasome }\end{array}$ & $\begin{array}{l}\text { BMDM, peritoneal macrophages, PBMCs } \\
\text { (FXR KO mice) }\end{array}$ & $\begin{array}{l}\text { Ameliorates partially the } \\
\text { symptoms of NLRP3-related } \\
\text { disease models }\end{array}$ & GW4064, INT747 & (83) \\
\hline LXR (NR1H) & $\begin{array}{l}\text { Induces the expression of IL-1 } 1 \beta \text {, } \\
\text { caspase- } 1 \text {, and NLRP3; Metabolic } \\
\text { rewiring through Acetyl-CoA accumulation }\end{array}$ & $\begin{array}{l}\uparrow \text { NLRP3 } \\
\text { inflammasome }\end{array}$ & Human monocytes & $\begin{array}{l}\text { Induction of trained innate } \\
\text { immunity }\end{array}$ & $\begin{array}{l}\text { GW3965, T1317 (agonist), } \\
\text { GSK2033 antagonist) }\end{array}$ & (84) \\
\hline LXR $\beta$ (NR1H2) & $\begin{array}{l}\text { Activates P2X7 receptor (non-genomic } \\
\text { activity) }\end{array}$ & $\begin{array}{l}\uparrow \text { NLRP3 } \\
\text { inflammasome }\end{array}$ & Colon cancer cell lines & $\begin{array}{l}\text { As a target for Caspase-1 } \\
\text { induced pyroptosis }\end{array}$ & T0901317 (agonist), LXR $\beta$ siRNA & (85) \\
\hline PXR (NR1/2) & $\begin{array}{l}\text { Enhances the expression of NLRP3 } \\
\text { through binding to its promoter region }\end{array}$ & $\begin{array}{l}\uparrow \text { NLRP3 } \\
\text { inflammasome }\end{array}$ & HUVECs, HepG2 & $\begin{array}{l}\text { Protects against xenobiotic } \\
\text { agents }\end{array}$ & $\begin{array}{l}\text { Rifampicin, SR12813 (agonists) } \\
\text { sulforaphane (antagonist) }\end{array}$ & (86) \\
\hline PXR & $\begin{array}{l}\text { Triggers release of ATP through } \\
\text { pannexin- } 1 \text { channels, P2X7 activation }\end{array}$ & $\begin{array}{l}\uparrow \text { NLRP3 } \\
\text { inflammasome }\end{array}$ & $\begin{array}{l}\text { Human macrophages (THP-1), Mouse } \\
\text { Peritoneal macrophages, NIrp3 KO and } \\
\text { PXR KO mice }\end{array}$ & $\begin{array}{l}\text { Link xenobiotic exposure to the } \\
\text { innate immunity as potential } \\
\text { conserved mechanism }\end{array}$ & $\begin{array}{l}\text { Rifaximin and SR12813 (for } \\
\text { human); 16a-carbonitrile (PCN) } \\
\text { (for mouse) }\end{array}$ & (87) \\
\hline PXR (NR1/2) & $\begin{array}{l}\text { Blocks NF-kB binding to the promoter of } \\
\text { NLRP3 }\end{array}$ & $\begin{array}{l}\downarrow \text { NLRP3 } \\
\text { inflammasome }\end{array}$ & HUVECS & $\begin{array}{l}\text { Statin via FXR act as an } \\
\text { anti-inflammatory agent }\end{array}$ & $\begin{array}{l}\text { Rifampicin, SR12813, } \\
\text { mevastatin, simvastatin }\end{array}$ & (88) \\
\hline $\begin{array}{l}\text { PPAR } \alpha(P P A R A, \\
\text { NR1C1) }\end{array}$ & $\begin{array}{l}\text { Knock out of PPAR } \alpha \text { associated with up } \\
\text { regulation in the inflammasome } \\
\text { components and hyper activation of } \\
\text { NF-kB pathway }\end{array}$ & $\begin{array}{l}\downarrow N \text { NLRP3 } \\
\text { inflammasome }\end{array}$ & $\begin{array}{l}\text { In vivo, PPAR } \alpha \text { KO mice subjected to P. } \\
\text { aeruginosa, lung tissue }\end{array}$ & $\begin{array}{l}\text { Protects lung tissue upon lung } \\
\text { bacterial infection }\end{array}$ & Not used & (89) \\
\hline $\begin{array}{l}\text { PPAR }(\text { PPARG, } \\
\text { NR1C3) }\end{array}$ & $\begin{array}{l}\text { Downregulates the expression } \\
\text { inflammasome components }\end{array}$ & $\begin{array}{l}\downarrow N \text { NLRP3 } \\
\text { inflammasome }\end{array}$ & $\begin{array}{l}\text { Radiation-induced acute intestinal injury } \\
\text { rat model, peritoneal macrophage }\end{array}$ & $\begin{array}{l}\text { Reduces radiation-induced } \\
\text { intestinal inflammation }\end{array}$ & Rosiglitazone & (90) \\
\hline $\begin{array}{l}\text { PPARY (PPARG, } \\
\text { NR1C3) }\end{array}$ & $\begin{array}{l}\text { Upregulates IFN- } \beta \text { which required for } \\
\text { suppression of NLRP3-mediated IL-1 } 1 \beta\end{array}$ & $\begin{array}{l}\text { PPAR } \gamma \text { KO mice } \\
\text { exhibit } \\
\text { downregulation of } \\
\text { NLRP3 } \\
\text { inflammasome } \\
\text { activation }\end{array}$ & $\begin{array}{l}\text { PPARy KO mice, Peritoneal macrophages, } \\
\text { in vivo peritoneal cytokine assessment }\end{array}$ & Anti-inflammatory & $\begin{array}{l}\text { T0070907 (antagonist) } \\
\text { Rosiglitazone }\end{array}$ & (91) \\
\hline $\begin{array}{l}\text { PPAR }(P P A R G, \\
\text { NR1C3) }\end{array}$ & $\begin{array}{l}\text { Inhibition of IL-1 } \beta \text {, caspase-1 and NLRP3 } \\
\text { expression }\end{array}$ & $\begin{array}{l}\downarrow \text { NLRP3 } \\
\text { inflammasome }\end{array}$ & $\begin{array}{l}\text { In vivo, spinal cord injury (rat). Isolated } \\
\text { Neurons from the spinal cord after spinal } \\
\text { cord injury (SCI) }\end{array}$ & $\begin{array}{l}\text { Anti-inflammatory protective } \\
\text { effects in spinal cord injury }\end{array}$ & $\begin{array}{l}\text { Rosiglitazone, G3335 } \\
\text { (antagonist) }\end{array}$ & $(92,93)$ \\
\hline $\begin{array}{l}\text { PPAR }(\text { PPARG, } \\
\text { NR1C3) }\end{array}$ & $\begin{array}{l}\text { Direct binding of PPARy to NLRP3, inhibits } \\
\text { its assembly }\end{array}$ & $\begin{array}{l}\downarrow N \text { NLRP3 } \\
\text { inflammasome }\end{array}$ & $\begin{array}{l}\text { Peritoneal macrophages, PPARGC/- mice, } \\
\text { (HEK293T cells/system), PBMCs }\end{array}$ & $\begin{array}{l}\text { Regulate metabolic DAMPs- } \\
\text { induced NLRP3 inflammasome }\end{array}$ & Rosiglitazone & (94) \\
\hline $\begin{array}{l}\text { PPAR (PPARD, } \\
\text { NR1C2) }\end{array}$ & $\begin{array}{l}\text { Modulation of AMPK activity and ROS } \\
\text { production, downregulates IL-1 } \beta \text {, } \\
\text { caspase- } 1 \text { and NLRP3, NLRP6, NLRP10 }\end{array}$ & $\begin{array}{l}\downarrow N L R P 3 \\
\text { inflammasome }\end{array}$ & NAFLD mouse model, HepG2 & $\begin{array}{l}\text { Ameliorates non-alcoholic fatty } \\
\text { liver disease associated } \\
\text { inflammation }\end{array}$ & GW501516 & (95) \\
\hline
\end{tabular}


TABLE 1 | Continued

\begin{tabular}{|c|c|c|c|c|c|c|}
\hline NR & Mechanism & Effect & Cell type & Possible therapeutic & Used ligand & References \\
\hline $\begin{array}{l}\text { PPARB } / \delta(P P A R D, \\
\text { NR1C2) }\end{array}$ & $\begin{array}{l}\text { Downregulation the expression of NLRP3 } \\
\text { inflammasome components }\end{array}$ & $\begin{array}{l}\downarrow N L R P 3 \\
\text { inflammasome }\end{array}$ & MPTP mouse model of PD & $\begin{array}{l}\text { Suppress NLRP3-mediated } \\
\text { neuroinflammation in PD mouse } \\
\text { model }\end{array}$ & GW501516 & (96) \\
\hline RAR (RAR) & $\begin{array}{l}\text { Enhances LPS -induced priming signal } \\
\text { and glycolytic activity }\end{array}$ & $\begin{array}{l}\uparrow N \text { NLRP3 } \\
\text { inflammasome }\end{array}$ & Human macrophage- derived monocyte & $\begin{array}{l}\text { Enhances inflammatory } \\
\text { responses }\end{array}$ & ATRA & (97) \\
\hline RAR (RAR) & $\begin{array}{l}\text { Reduced level of ROS and endotoxins in } \\
\text { circulation }\end{array}$ & $\begin{array}{l}\downarrow \mathrm{NLRP3} \\
\text { inflammasome }\end{array}$ & Rat, in vivo study, total blood & $\begin{array}{l}\text { Ameliorates alcohol toxicity in the } \\
\text { brain }\end{array}$ & ATRA & (98) \\
\hline $\begin{array}{l}\text { RAR, RXR (RAR) } \\
(R X R)\end{array}$ & $\begin{array}{l}\text { Enhances flagellin-induced NF-кB/AP-1 } \\
\text { activity, and TLR co-receptor CD14 }\end{array}$ & $\uparrow \mathrm{IL}-1 \beta$ Release & THP-1 (human monocyte) & $\begin{array}{l}\text { Enhances flagellin-induced } \\
\text { proinflammatory responses }\end{array}$ & $\begin{array}{l}\text { ATRA, BMS753 (RAR } \alpha \text { agonist), } \\
\text { LG100268 (RXR } \alpha \text { agonist) }\end{array}$ & (99) \\
\hline $\begin{array}{l}\text { REV-ERB } \alpha \\
\text { (NR1D1) }\end{array}$ & $\begin{array}{l}\text { Suppress NLRP3 transcription by binding } \\
\text { to its promoter, and inhibit NF-kB signaling }\end{array}$ & $\begin{array}{l}\downarrow N L R P 3 \\
\text { inflammasome }\end{array}$ & $\begin{array}{l}\text { REV-ERB } \alpha \text { KO mice } \\
\text { Peritoneal macrophage, RAW264.7, } \\
\text { DSS-induced colitis mouse model }\end{array}$ & Suppress experimental colitis & SR9009, hemin, GSK4112 & $(100)$ \\
\hline $\begin{array}{l}\text { REV-ERB } \alpha \\
\text { (NR1D1) }\end{array}$ & $\begin{array}{l}\text { Repress NLRP } 3 \text { and IL- } 1 \beta \text { transcription by } \\
\text { binding to its promoter }\end{array}$ & $\begin{array}{l}\downarrow \text { NLRP3 } \\
\text { inflammasome }\end{array}$ & $\begin{array}{l}\text { REV-ERB } \alpha \text { KO mice } \\
\text { RAW264.7, human macrophage, } \\
\text { peritonitis and } \\
\text { LPS/D-Galactosamine-induced fulminant } \\
\text { hepatitis mice models }\end{array}$ & $\begin{array}{l}\text { Suppress experimental } \\
\text { peritonitis and fulminant hepatitis }\end{array}$ & $\begin{array}{l}\text { SR9009, hemin, SR10067 } \\
\text { (REV-ERB } \alpha / \beta \text { agonist) }\end{array}$ & (101) \\
\hline $\begin{array}{l}\text { RORy (RORC, } \\
\text { NR1F3) }\end{array}$ & $\begin{array}{l}\text { Response elements for ROR } \gamma \text { in the } \\
\text { promoters of the NIrp3 and Il1b genes }\end{array}$ & $\begin{array}{l}\text { ROR } \gamma \text { KO mice } \\
\text { exhibit } \\
\text { downregulation of } \\
\text { NLRP3 } \\
\text { inflammasome }\end{array}$ & $\begin{array}{l}\text { BMDMs (ROR } \gamma \text { KO mice), human primary } \\
\text { macrophages, RAW267 }\end{array}$ & Anti-inflammatory & $\begin{array}{l}\text { SR2211, SR1555 (inverse } \\
\text { agonist) }\end{array}$ & (102) \\
\hline SHP (NROB2) & $\begin{array}{l}\text { Inhibits interaction between NLRP3 and } \\
\text { ASC }\end{array}$ & $\begin{array}{l}\downarrow \text { NLRP3 } \\
\text { inflammasome }\end{array}$ & BMDM, SHP KO mice, HEK293T, THP-1 & $\begin{array}{l}\text { Anti-inflammatory, protect } \\
\text { against excessive pathologic } \\
\text { responses, preserve the } \\
\text { mitochondrial homeostasis }\end{array}$ & Fenofibrate, AICAR & (103) \\
\hline $\operatorname{VDR}(\operatorname{VDR}, N R 1 / 1)$ & $\begin{array}{l}\text { Attenuates hyperosmotic stress-induced } \\
\text { oxidative stress through activation } \\
\text { NRF2-antioxidant axis }\end{array}$ & $\begin{array}{l}\downarrow \text { NLRP3 } \\
\text { inflammasome }\end{array}$ & $\begin{array}{l}\text { Immortalized primary human corneal } \\
\text { epithelial cell }\end{array}$ & $\begin{array}{l}\text { Potential therapeutic agent to } \\
\text { treat dry eye problems }\end{array}$ & Calcitriol (1,25-D) & (104) \\
\hline $\operatorname{VDR}(V D R, N R 1 / 1)$ & $\begin{array}{l}\text { Suppress NF-kB nuclear translocation } \\
\text { through binding to importin } 4\end{array}$ & $\begin{array}{l}\downarrow \text { NLRP3 } \\
\text { inflammasome }\end{array}$ & $\begin{array}{l}\text { MRL/lpr mice, Mouse renal tubular } \\
\text { epithelial cells }\end{array}$ & $\begin{array}{l}\text { Potential therapeutic agent for } \\
\text { lupus nephritis }\end{array}$ & Paricalcitol (agonist) & $(105)$ \\
\hline $\operatorname{VDR}(\operatorname{VDR}, N R 1 / 1)$ & $\begin{array}{l}\text { Inhibits NLRB3 binding to NEK7, } \\
\text { NLRP3-mediated (ASC) oligomerization, } \\
\text { and (ROS) accumulation }\end{array}$ & $\begin{array}{l}\downarrow \text { NLRP3 } \\
\text { inflammasome }\end{array}$ & $\begin{array}{l}\text { Peritoneal macrophages, DSS-induced } \\
\text { ulcerative colitis mouse model }\end{array}$ & $\begin{array}{l}\text { Attenuates DSS-induced acute } \\
\text { colitis in mice, inhibits CD4+ T } \\
\text { cells generation and polarization } \\
\text { Decrease M1/M2 macrophages } \\
\text { ratio }\end{array}$ & Calcitriol (1,25-D) & (106) \\
\hline $\operatorname{VDR}(\operatorname{VDR}, N R 1 / 1)$ & $\begin{array}{l}\text { Enhances IL-1 } \beta \text { secretion mediated by } \\
\text { NLRP3 inflammasome }\end{array}$ & $\begin{array}{l}\uparrow \text { NLRP3 } \\
\text { inflammasome }\end{array}$ & PMA-differentiated THP-1 & Enhances inflammatory response & $\begin{array}{l}\text { 1,25(OH)2D3, 25(OH)D3, 7DHC, } \\
\text { vitamin D3 }\end{array}$ & $(107)$ \\
\hline $\operatorname{VDR}(\operatorname{VDR}, N R 1 / 1)$ & $\begin{array}{l}\text { Direct interaction with NLRP3, Inhibits } \\
\text { BRCC3-mediates NLRP3 deubiquitylation }\end{array}$ & $\begin{array}{l}\downarrow N L R P 3 \\
\text { inflammasome }\end{array}$ & $\begin{array}{l}\text { BMDMs, mouse peritoneal macrophages } \\
\text { (Vdr KO mice) }\end{array}$ & $\begin{array}{l}\text { Anti-inflammatory, increases the } \\
\text { survival rate in murine models of } \\
\text { sepsis }\end{array}$ & $1,25-\mathrm{D}$ & (108) \\
\hline $\operatorname{VDR}(V D R, N R 1 / 1)$ & $\begin{array}{l}\text { Modulates AhR/NF-кB signaling, } \\
\text { downregulate inflammasome components }\end{array}$ & $\begin{array}{l}\downarrow \mathrm{NLRP3} \\
\text { inflammasome }\end{array}$ & $\begin{array}{l}\text { Periodontitis mouse model, gingival } \\
\text { epithelium }\end{array}$ & Alleviates the periodontitis & $1,25-\mathrm{D}$ & (109) \\
\hline
\end{tabular}




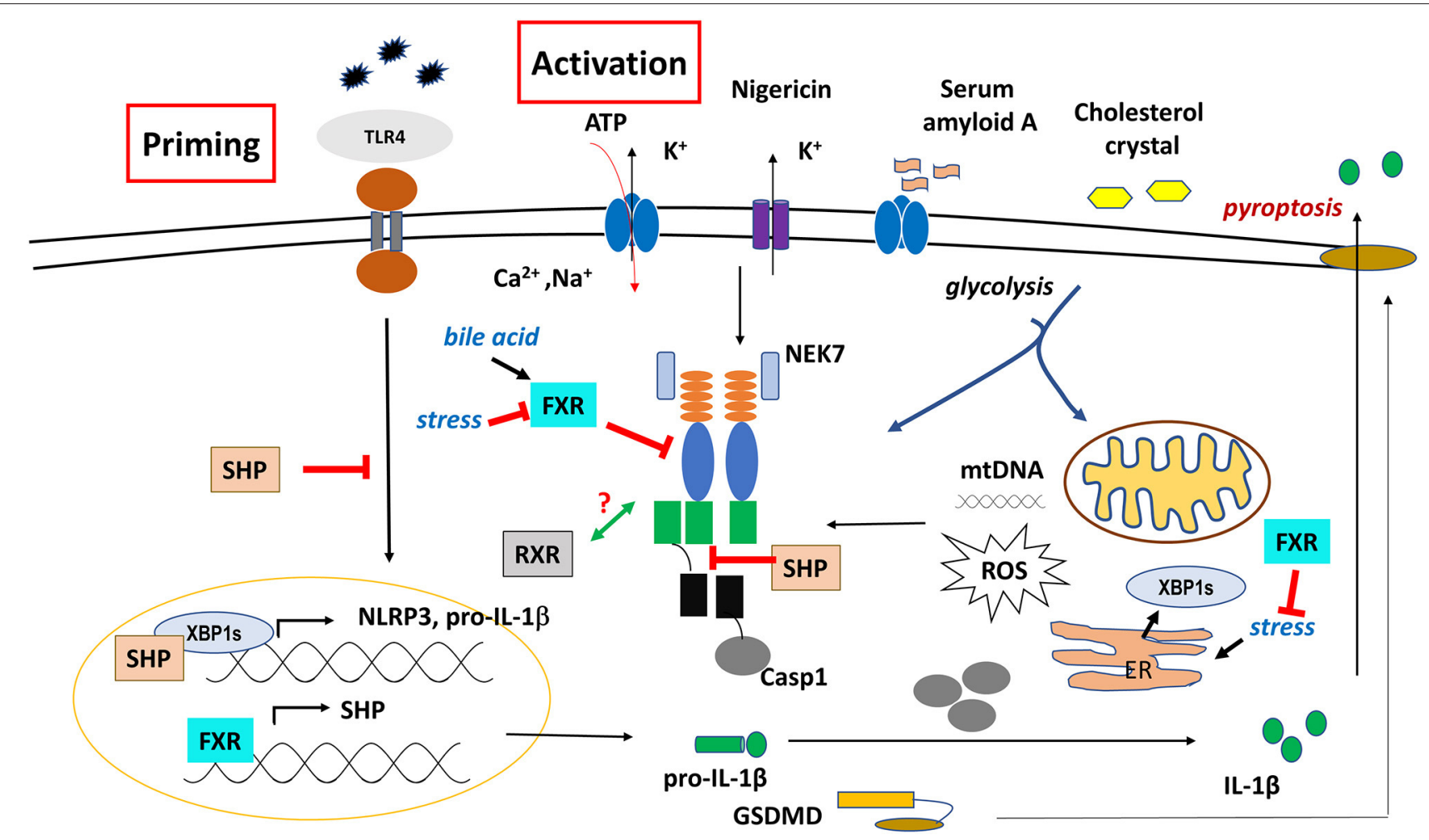

FIGURE 3 | Regulatory role of SHP, FXR, and RXR on NLRP3 inflammasome functions. The effect of SHP is controversial, probably it depends on the cell or tissue type.

\section{Farnesoid X Receptor (FXR)}

FXR; as a transcription factor, binds to DNA either as a monomer or as a heterodimer with RXR. Together with PXR and VDR, it belongs to the group of metabolic nuclear receptors, and is basically considered as a sensor for endogenous bile acids (BAs), and a key regulator for bile acids homeostasis (123). It is mainly expressed in the liver and intestine, as well as in various immune cells (including macrophages, dendritic cells (DCs) and T-cells) $(124,125)$.

Studies show that FXR mediates cell-type specific functions. In hepatocytes, FXR, as a key regulator of bile acids synthesis, senses both primary and secondary bile acids with different affinity, and initiates transcriptional regulation of gene sets; including SHP, in order to inhibit further bile acid synthesis, in a negative feedback mechanism. SHP mediates transcriptional repression of several genes; including CYP7A1, a rate-limiting enzyme in bile acid synthesis. The intestinal FXR mediates bile acids transportation through regulation of several transporters involved in this process. Furthermore, upon activation, FXR mediates fibroblast growth factor 15 (FGF-15) (FGF-19 in humans) secretion, which translocates through portal circulation, and binds the basolateral fibroblast growth factor receptor 4 (FGFR4) in hepatocytes, mediating transcriptional inhibition of CYP7A1 (123, 125, 126). While FGF is important for bile acids, glucose, and lipid homeostasis, protecting against hepatosteatosis, in mice fed a high fat diet, lack of FGF results in increased hepatosteatosis, associated with endoplasmic reticulum (ER) stress and impaired tissue regeneration (127). Furthermore, activation of FXR/SHP axis also inhibits PXR-, LXR-, and PPAR $\alpha$-mediated CYP7A1 gene transcription, and reduces the expression of SREBP1, a member of the basic helix-loop-helixleucine zipper (bHLH-Zip) transcription factor family, that is involved in lipogenesis (127-130).

Recent reviews demonstrated that the function of FXR is far more than being simply a bile acids regulator, as it participates in a dynamic network of lipid and glucose metabolism, it maintains the homeostasis in different tissues and organs, and has various regulatory roles in innate immune responses (125, 131). Like in hepatocytes and macrophages FXR inhibits NFkB signaling and suppress proinflammatory cytokine secretion under inflammatory conditions $(132,133)$. Furthermore, it mediates M2 polarization of macrophages, and modulates DC differentiation to promote anti-inflammatory effects. In mouse colitis model, it upregulates IL-10 expression and reduceses DC and effector $\mathrm{T}$ cell infiltration, while recruits Treg to the colonic inflammatory site (123-125).

FXR was originally shown to be activated by an excessive level of farnesol; an intermediate metabolite of the mevalonate pathway. In fact, dysregulation of the mevalonate pathway has been linked to the innate immune function and Pyrinand NLRP3 inflammasome activation $(134,135)$. Activation of FXR by various ligands leads to the upregulation of CYP3A 
expression, which hydroxylates ATRA, an RAR agonist, and accelerates its catabolism. This indicates that FXR may regulate RAR-mediated signaling by modulating ATRA availability (136). Furthermore, FXR is known as a repressor of autophagy, and the activation of FXR induces transcriptional repression of autophagy genes (such as such as, Ulk1, Lc3a, Lc3b, Gabarap, Wipl1, Wipl2, and several Atg genes) (137), and autophagy protein and vesicles even under nutrient deprivation condition (123).

The effect of FXR on inflammasome-related functions and cytokine secretion seems to be complex, and in some cases controversial, possibly due to differences in the studied conditions. The activation of macrophages and Kupffer cells by bile acids induces the secretion of inflammatory cytokines; such as IL- $1 \beta$ and TNF- $\alpha$, which in turn, also inhibit CYP7A1 gene transcription through activation of PKC and JNK kinase signaling pathways (129). Any defect in the flow of bile acids was delineated as cholestasis, and can be associated with sepsis (138). FXR-null mice exhibited deregulation in bile acids, glucose and lipoprotein metabolism, and had a high risk of hepatocellular carcinoma (HCC) and other degenerative liver diseases, in addition to abnormalities in the function of the intestinal-epithelial barrier (139-141). Furthermore, activation of intestinal FXR by bile acids induced the expression of a group of genes involved in mucosal defense, which inhibited bacterial overgrowth and prevented deterioration of the intestinal epithelial barrier (142).

In human and mouse differentiated macrophages, increase in bile acids over the physiological level is considered as a DAMP, and can initiate the priming signal (signal 1) by enhancing the expression of IL-1 $\beta$ and NLRP3, and activate the NLRP3 inflammasome through promoting prolonged calcium influx (signal 2) (81, 138) (Figure 3). In sepsis-associated cholestasis mouse model, FXR-null mice were found to be more susceptible to LPS-induced death, had high level of bile acids in the serum, and the isolated peritoneal macrophages exhibit higher activation of caspase-1/IL-1 $\beta$ compare to the wild type cells under LPS challenge. Treatment with cholestyramine resin; a bile acid sequestrant, or overexpression of FXR, restored the serum level of bile acids, improved their survival, and repressed the caspase1 and IL-1 $\beta$ activation. However, intraperitoneal treatment with GW4064; an FXR agonist, did not protect the mice from this septic shock. Importantly, a co-immunoprecipitation analysis revealed that FXR may physically interact with NLRP3 inflammasome components, hence, prevent their assembly and repress the activation of NLRP3 inflammasome in a ligandindependent manner (81).

Conversely however, other report showed that several bile acids derivatives suppressed LPS/nigericin-induced NLRP3 inflammasome activation in BMDMs, through TGR5cAMP-PKA axis, mediating ubiquitination and subsequent phosphorylation of NLRP3 at a single residue (Ser 291), which led to the inhibition of NLRP3 inflammasome activation (143). However, activation of FXR by its agonist INT-747 had no effect on NLRP3 ubiquitination, suggesting that FXR is not involved in bile acid-induced NLRP3 inflammasome suppression (143).
Recently, a study showed that down-regulation of FXR expression correlated with the high expression of inflammasomeassociated genes, and induced inflammasome activation in various liver diseases. Furthermore, tunicamycin-induced ER stress animal model exhibited down-regulation of hepatic FXR, in association with up-regulation of NLRP3 and TXNIP levels and NLRP3 inflammasome activation. These effects were exaggerated under the loss of FXR, while treatment with FXR agonist GW4064 ameliorated NLRP3 activation. They also showed that under ER stress, loss of FXR resulted in the upregulation of $\mathrm{p}$-PERK, and $\mathrm{CHOP}$; typical regulators of ER stress response (82). Notably, during the ER stress response, PERK and XPB1 mediate CHOP expression, which is involved in apoptosis and NLRP3 inflammasome activation, leading to caspase- 1 cleavage, IL- $1 \beta$ secretion and pyroptosis. CHOP as a transcriptional regulator mediates NLRP3 and TXNIP expression $(82,144)$. In line with these results, ligated FXR inhibited pPERK- and CHOP- mediated ER stress and subsequent NLRP3 inflammasome activation. This inhibition was most likely due to the attenuation of miR-186-mediated inhibition of NCK1, which is a regulator of PERK/CHOP axis (82).

Because of their safety profiles and proven efficacy, several steroid and non-steroid FXR agonists; such as GW4064, WAY362450, Px-104, and INT747, were developed to overcome liver- associated diseases (145). However, they still require further investigation, to understand their impact on the inflammatory mechanisms. In BMDMs, FXR agonist GW4064; but not INT747, inhibited NLRP3 and AIM2 inflammasomes activation in an FXR-independent manner, while it had no effect on NLRC4 inflammasome. This molecule had the ability to attenuate ASC oligomerization through the reduction of ASC ubiquitination, leading to impairment in both NLRP3-ASC interaction and ASC oligomerization (83). It was reported that the expression of FXR was downregulated following hepatic ischemia reperfusion injury (IRI) in mouse model. In this model, deletion of FXR was associated with induction of NLRP3 inflammasome-mediated GSDMD-N and caspase- 1 cleavage, and an increased pyroptosismediated liver damage was observed (146). In IRI model, GW4064 treatment reduced the secretion of proinflammatory cytokines, including that of IL- $1 \beta$. Compared to BMDMs, FXR is highly expressed in Kupffer cells. Knock-down of SHP or depletion of Kupffer cells abolished FXR-mediated inhibition of liver inflammatory genes (147).

Altogether, these findings suggest that FXR plays a crucial role in the regulation of inflammasome function. However, the role of FXR is influenced by various factors, including the expression level of FXR in different cells and tissues, the type and differentiation status of the immune cell, study conditions, or the type and affinity of the endogenous/exogenous FXR ligands. Notably, FXR ligands may also have a direct effect on the inflammasome in an FXR-independent manner. Furthermore, bacterial endotoxins markedly downregulate the expression of FXR, which may explain sometimes controversial reports regarding NLRP3 inflammasome. Importantly, FXR may also affect inflammasome function indirectly, by regulating the expression and function of other nuclear receptors (e.g., FXRSHP axis). 
Nowadays, FXR ligands are under clinical trials targeting human metabolic dysregulation-associated diseases; such as obesity, type 2 diabetes, or liver diseases (148). A screening of more than a thousand FDA/EMA-approved drug revealed that some of them modulated the activity FXR, hence, FXR may affect the outcome of various therapies. Nevertheless, FXR may open an opportunity for polypharmacology, particularly in inflammasome-related diseases (148).

\section{Pregnane X Receptor (PXR)}

PXR exhibits distinctive large, flexible and dynamic LBD to accommodate a broad spectrum of hydrophobic ligands with various structural and physicochemical characteristics. These ligands may include natural steroids (such as progesterone, corticosterone), synthetic drugs (like dexamethasone), antibiotics (like rifampicin), bile acid, herbal compounds and environmental toxicants $(149,150)$. PXR is considered as a master xenobiotic sensor that; upon activation, heterodimerizes with RXR to regulate a set of downstream genes, such as enzymes of the mitochondrial cytochrome P450 family (mainly CYP3A and CYP2b), various transferases (like GST1) and ABC transporters (like MDR) mainly required in detoxification. Due to its central regulatory role in detoxification, activation of PXR may lead to clinical consequences like drug resistance or drugdrug interactions-induced toxicity that may severely affect the outcome of a therapy $(151,152)$.

Several molecules and mechanisms have been described as positive, or negative regulators of PXR's activity. Like transcriptional co-activators (SRC-1, RIP140, PGC-1) or co-repressors (NCoR, SMRT) that are recruited to PXRRXR following ligand binding. Besides, various signaling pathways (NFkB, AP-1, PKA, PKC, CDK, etc.) and posttranslational modifications of PXR (phosphorylation, acetylation, SUMOylation, ubiquitination) may potentiate or terminate the activity of PXR. Interestingly, a reciprocal connection between PXR and NFKB pathways has been reported, in which activation of one pathway suppresses the activity, and expression of the target genes for the other (153). Activity of PXR is also regulated via crosstalk with other nuclear receptors (CAR, VDR, HNF4a) or transcription factors (CREB, FOXO, NFkB), like LXR, FXR, or PPARs by sharing or competing for the binding of co-regulatory molecule or response element on the target gene (154-156).

PXR is highly expressed in the liver and intestine, but functions in many other tissues and different cell types, hence, it affects several physiological and immunological functions, including metabolism, inflammation, cell cycle and apoptosis. sometimes with contradictory results. Interestingly, tissue- and species-specific ligands for PXR have also been identified. For example, in the vascular endothelium of the aorta and pulmonary vessels, PXR activation by indole 3-propionic acid (IPA); a circulating tryptophan metabolite of intestinal microbiota, inhibits eNOS-mediated NO production, consequently leading to vasoconstriction of the blood vessels (157). While in mesenteric arteries, vasodilation was induced by the PXR agonist progesterone metabolite, probably via the induction of CYP enzymes. Furthermore, rifaximin which is a gut-specific human
PXR ligand, is not effective for rodents; while pregnenolone16 alpha carbonitrile (PCN) functions as a rodent-specific ligand (158-161).

PXR is also expressed in immune cells; such as including B- and T cells, as well as macrophages. Myeloid-specific PXR deficiency was shown to lead to reduction of atherosclerosis as a result of reduced lipid uptake and foam cell formation (162). PXR ameliorates acute kidney injury by regulating AKR1B7 which attenuates mitochondrial dysfunction, and leads to improvement in lipid metabolism (163). These data suggest that PXR is involved in several mechanisms that are potentially connected to the regulation of NLRP3 inflammasome, which also serves as a sensor for potentially dangerous or foreign molecules.

It was shown that treatment of human umbilical vein endothelial cells (HUVECs) with PXR agonist (rifampicin or SR12813), or overexpression of PXR induced the expression of various NLRs (NOD1 NLRP1, NLRP3) and TLRs (TLR2, TLR4, TLR9). PXR was shown to induce NLRP3 inflammasomemediated caspase- 1 and IL-1 $\beta$ cleavage, and silencing of PXR or treatment with PXR antagonist (sulforaphane) diminished these effects. Importantly, using CHIP and promoter-reporter based assays, several PXR-responsive elements (PXREs) were identified in the NLRP3 promoter region, indicating a direct regulatory role of PXR in NLRP3 priming signal (86) (Figure 4). In line with this, activation of PXR with species-specific ligands induced NLRP3 inflammasome-dependent caspase-1 activation, and IL-1 $\beta$ release in human THP-1 and LPSprimed mouse macrophage. PXR activation triggered rapid release of cellular ATP through pannexin-1 channel, leading to $\mathrm{P} 2 \mathrm{X} 7$ receptor activation and subsequent NLRP3 inflammasome activation, suggesting a non-genomic function for PXR in NLRP3 inflammasome activation (87).

Nevertheless, PXR was reported to mediate the inhibitory effect of statins (simvastatin or mevastatin) on ox-LDL- or TNF$\alpha$-induced NLRP3 activation, as well as reduced NF-kB binding to the promoter of NLRP3 in endothelial cells. Knockdown of PXR abolished statin- or PXR agonist-mediated suppression of NLRP3 inflammasome activation (88). Altogether, these data suggest important, yet versatile roles for PXR in innate immunity, and cellular homeostasis under xenobiotic challenges. Considering that both PXR and NLRP3 sense xenobiotics, and a huge variety of (harmful) molecules, they also share and use an overlapping pathway during their function, the two systems deserve further studies in order to delineate cellspecific mechanisms of the potential "crosstalk" between PXR and NLRP3 inflammasome.

\section{Liver X Receptor (LXR)}

LXRs (LXR $\alpha$ and LXR $\beta$ ) form permissive heterodimers with RXR. While the expression of $\mathrm{LXR} \alpha$ is mainly restricted to adipose tissue, liver, intestine, and macrophages; LXR $\beta$ may present in all types of cells and tissues. LXRs are considered as cholesterol sensors, and activation of LXRs with its endogenous agonist (oxysterol) modulates the expression of genes related to lipid metabolism, especially fatty acid synthesis [such as fatty acid synthase (FASN)] and cholesterol efflux (ABCG1) (164). In the liver, LXR senses elevated cholesterol level, and activates the 


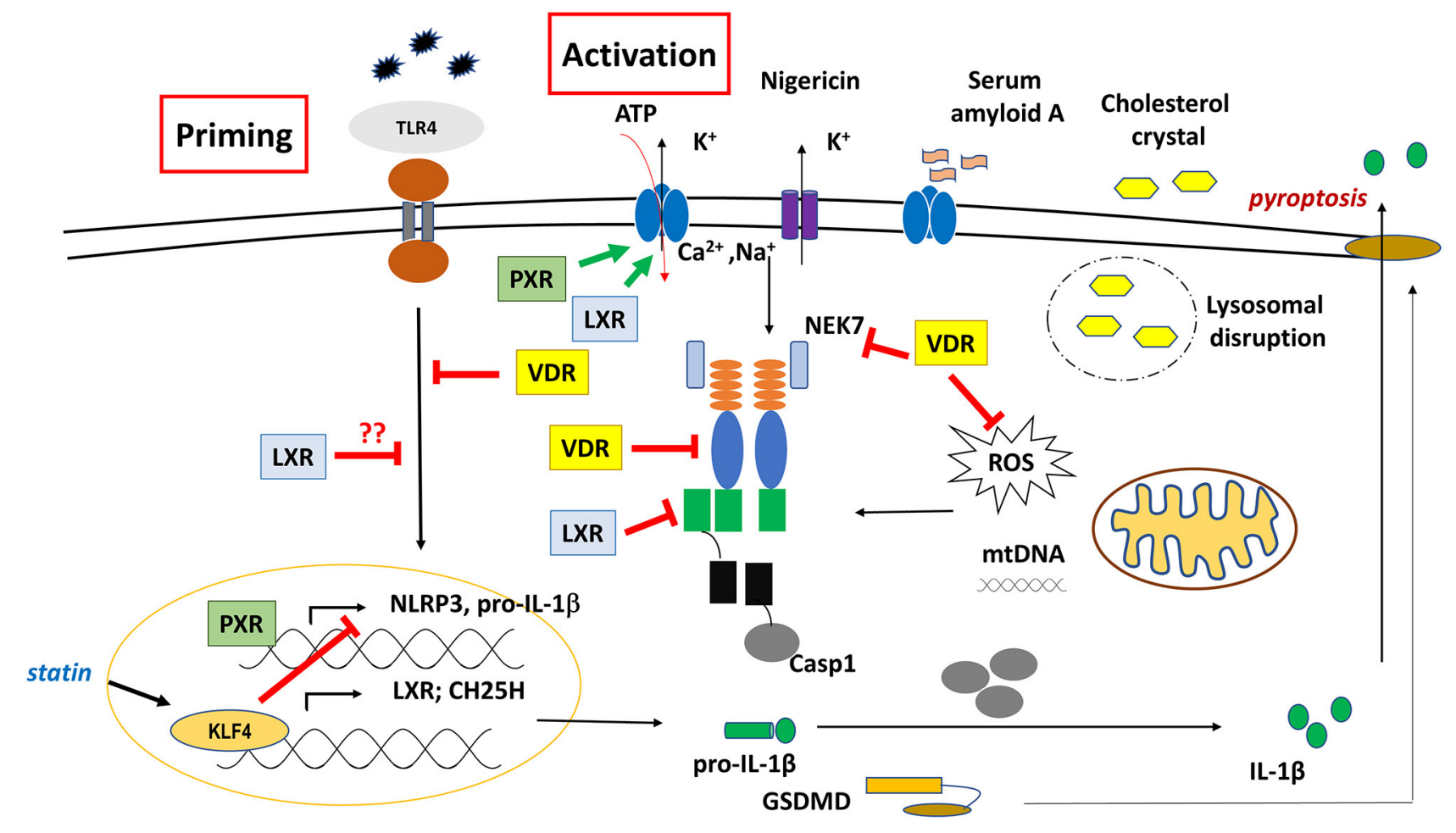

FIGURE 4 | Regulatory role of VDR, PXR, and LXR on NLRP3 inflammasome functions.

expression of CYP7A1; the rate-limiting enzyme of neutral bile acid synthesis.

At the sites of the atherosclerotic lesions, macrophages usually become foam cells by accumulating excess cholesterol. Importantly, cholesterol crystals in macrophages are important inducers of inflammatory signaling, including inflammasomemediated IL-1b secretion, which is a major driver of tissue damage developed in atherosclerotic lesions (165, 166). However, in mouse model of atherosclerosis, LXR agonists were shown to dramatically decrease lesion formation (167), through modulating the function of macrophages. LXR agonist induce reverse cholesterol transport (RCT) in macrophages by enhancing the expression of cholesterol efflux transporter ABCA1 and ABCG1 (168). However, LXR not only mediates transactivation of genes with LXR responsive elements for RCT in macrophages. LXR may also attenuate the inflammatory response in a ligand-specific SUMOylation-dependent "transrepression" mechanism. Interestingly, upon binding of synthetic agonist (GW3965) or some endogenous oxysterol, such as 22R, 24(S), $25 \mathrm{EC}$, and $24 \mathrm{HC}$; but not $25 \mathrm{HC}$ or $27 \mathrm{HC}$, LXR is targeted to sumo-modification to recruit co-repressor NCoR/SMART molecules. The whole complex then interacts with $\mathrm{NF \kappa B}$, and is recruited to $\mathrm{NF \kappa B}$ binding site of proinflammatory target genes, in order to inhibit their expression $(169,170)$. Thus, it seems that while intracellular sterols trigger inflammatory responses, at the same time, they also activate LXR, which in turn initiates an anti-inflammatory pathway to limit inflammation (171). As the effect of LXR on inflammatory responses is still controversial due to the various model systems $(172,173)$, the potentially regulatory role of LXR on the NLRP3-mediated mechanisms also requires further in-depth studies.

Beside modulating NFkB signaling, LXR possess other forms of non-genomic functions to regulate NLRP3 inflammasome functions. LXRs were found to be expressed in various cancer cell lines, and regulate cell proliferation, and cell death. In both human and mouse colon cancer cell lines, it was shown that T0901317; a synthetic ligand for LXR, induced NLRP3 inflammasome-mediated caspase- 1 activation. Mechanistically, it was shown that the ligand-activated LRX $\beta$ interacted with pannexin-1. Activation of the channel resulted in ATP secretion, and eventually, it led to the activation of $\mathrm{P} 2 \mathrm{X} 7$ purinergic receptor; a major driver of NLRP3 inflammasome activation. The ability of LXR $\beta$ to mediate caspase- 1 activation was associated with pyroptosis-mediated cell death that resulted in the reduction of tumor growth in mice model (85) (Figure 4). This mechanism may provide more insight about LXR- $\beta$ /pyroptosis axis as a target candidate for cancer therapy.

Cerebral inflammatory demyelination is the major feature of childhood cerebral ALD (CCALD). In an iPSC model of CCALD using microarray-based transcriptional profiling analysis, significant up-regulation of cholesterol 25-hydroxylase $(\mathrm{CH} 25 \mathrm{H})$ expression was detected, and in line with this, an elevated 25-hydroxycholesterol (25-HC) (typical agonist of LXR) was measured, which are major risk factors of cerebral inflammation and contributors of neurodegenerative diseases (174). Following in vivo injection of 25-HC into the corpus 
callosum of wild-type mouse brains, recruitment of Iba1 positive microglia and elevated level of IL-1 $\beta$ was detected in the injected region. In vitro treatment of LPS-activated BMDM with 25-HC also increased IL-1 $\beta$ secretion via NLRP3 inflammasome activation. They showed that $25-\mathrm{HC}$ enhanced Kefflux and the production of mtROS, and these mechanisms could be inhibited by the LXR antagonist, 22(S)-hydroxycholesterol [22(S)-HC] (175).

However, importantly, a later study identified Krüppellike factor 4 (KLF4) as an important inducer of $\mathrm{CH} 25 \mathrm{H}$ expression in endothelial cells as well as in macrophages (176). KLF4 is a master transcription factor that regulates antiinflammatory responses, aiding in the transition of macrophages from M1 to M2 phenotype $(176,177)$. This study showed that the promoter region of $\operatorname{LXR} \alpha$ possessed binding sites for KLF4, and that the overexpression of KLF4 induced the expression of LXR $\alpha$ and cholesterol 25-hydroxylase $(\mathrm{CH} 25 \mathrm{H})$, while it inhibited the expression of the NLRP3 inflammasome components. Furthermore, using LC-TMS, they detected an elevated concentration of 25-HC in KLF4-transfected THP1 monocytes. Treatment of BMDM with $25-\mathrm{HC}$ resulted in increased $\mathrm{CH} 25 \mathrm{H}$ and LXR; and decreased NLRP3 levels. The study concluded that atheroprotective factors (such as statins or pulsatile shear stress) induced KLF4 expression in endothelial cells and macrophages, which mediated expression of $\mathrm{CH} 25 \mathrm{H}$ and LXR. Due to the activity of $\mathrm{CH} 25 \mathrm{H}$, intracellular 25-HC level was elevated; which acting as an LXR agonist, induced cholesterol efflux genes (like ABCA1) and suppressed pro-inflammatory gene expression, including that of the NLRP3 inflammasome components (178).

Similar to these findings, using LPS-primed BMDM or peritoneal macrophages, synthetic LXR agonists (T0901317; T09) significantly inhibited NLRP3 inflammasome activation by abolishing ASC oligomerization, mtROS generation, and the transcription of NLRP3 and pro-IL-1 $\beta$ (179). In line with these results, LXR synthetic agonists T09 significantly downregulated the expression of NLRP 3 and caspase- 1 in microglia that were activated with intravitreal injection of Amyloid $\beta$ (A $\beta 1-40)$ (178). The inhibitory effect of T09 was explained by the inhibition of IkB phosphorylation.

Another study aimed to delineate the potential protective role of LXR following irradiation, in order to enhance shifting of macrophage polarization from M2 to M1 phenotype, which is a preferred form to fight in tumorous conditions. Using immortalized BMDMs (iBMDM), LXR activation was found to mediate protection against ionizing radiation. Following irradiation in LXR-deficient BMDMs, significantly increased p53 expression, caspase-1 activity and subsequent pyroptosis, as well as pro-inflammatory cytokine production was detected. They concluded that ionizing radiation of LXR-deficient or LXR antagonist-pretreated macrophages promoted macrophage polarization toward a pro-inflammatory (M1) type, however, irradiation markedly reduced their viability as a result of the enhanced pyroptosis (180).

On the contrary however, the activation of LXR by synthetic ligands is associated with induction of the trained innate immunity and proinflammatory phenotype in human monocytes. The trained innate immunity was dependent on NLRP3 inflammasome-mediated IL- $1 \beta$ production, which was associated with up-regulation in the expression of NLRP3 and IL- $1 \beta$ upon LXR activation (84).

LXR has been also reported to regulate IL-18 expression in primed BMDM via multiple mechanisms. It was shown that activation of LXR downregulated the LPS-induced gene expression of IL-18, pro-IL-1 $\beta$ and pro-caspase-1, without effecting NLRP3 expression. However, at the same time, LXR activation induced the expression of IL-18BP; an IL-18 decoy receptor. Mechanistically it was shown that activation of LXR augmented the binding of IRF8 transcription to the promoter of IL-18BP, this way facilitating IL-18BP expression that consequently participated in the reduction of IL-18 cytokine level (181).

These results altogether indicate, that though LXR may regulate NLRP3 inflammasome function at multiple level, further studies are needed to clarify molecular mechanisms.

\section{Peroxisome Proliferator-Activated Receptors (PPARs)}

PPARs regulate gene transcription by forming permissive heterodimers with retinoid $\mathrm{X}$ receptors. They are generally activated by a diverse group of fatty acids and their derivatives, a variety of eicosanoids, and a number of selective synthetic drugs. PPARs coordinate lipid and glucose metabolism, and they are drug targets in hypertriglyceridemia and insulin resistance. Dysfunction of PPARs may lead to perturbation of lipid metabolism that is characteristic in metabolic syndromes (obesity, atherosclerosis), and is accompanied by low-grade chronic inflammation termed "sterile inflammation" with continuous production of pro-inflammatory cytokines including IL-1 $\beta$. At the same time, dysregulated lipid metabolism may also lead to the decrease of endogenous lipid ligands for PPARs, resulting in the disturbance of mitochondrial development and function, release of mitochondrial DNA, and elevated mtROS. Elevation of the cytosolic danger signals (such as mtDNA and mtROS) develop cellular stress that may eventually lead to enhanced inflammatory responses (182). A thorough review has been published recently about the role of PPARs in immune responses (183). Importantly, though all PPARs play a major regulatory role in energy homeostasis, each of them has a characteristic location of expression and distinct functions in the tissues, hence, they may intervene in inflammatory responses by various way.

\section{PPAR $\gamma$}

$\operatorname{PPAR} \gamma$ is mostly expressed in white adipocytes, but can also be found in the kidney, liver, intestine, skeletal muscle, breast, prostate as well as in a variety of immune cells like macrophages, dendritic cells, eosinophils, T cells and B cells (184, 185). Increased expression of PPAR $\gamma$ was documented at sites of inflammation such as in arthritis, colitis, and in foam cells from atherosclerotic plaques. PPAR $\gamma$ is essential to the regulation of white adipocyte differentiation, and plays a critical role in lipid (energy) storage, glucose metabolism and insulin sensitivity. In brown adipose tissue, it regulates the expression of mitochondrial proteins (such as the PGC- 1 txnal coregulatory of PPARg, or 
UCP-1 responsible for thermogenic respiration), and members of the electron transport chain. In macrophages, it drives foam cell formation in atherosclerosis, as it induces the expression of CD36 scavenger receptor and fatty acid transporter that regulates oxLDL uptake into the cells $(186,187)$. PPAR $\gamma$ is activated by naturally occurring ligands, including prostaglandins (15deoxyPGJ2), and oxidized low density lipoprotein (ox-LDL), as well as by synthetic agents such as thiazolidinedione antidiabetic drugs and non-steroidal anti-inflammatory drugs (NSAIDs), thus, PPAR $\gamma$ is the most common PPAR isoform targeted for therapeutic interventions.

Regarding inflammatory responses, while PPAR $\gamma$ does not regulate MF differentiation, it was shown to exert a variety of anti-inflammatory effects, in part, by repressing numerous NFkB target genes. These effects are either mediated through direct physical interactions and sequestration of NFKB coactivators, or in a DNA-independent way, mainly by impairing phosphorylation of the signaling factors. Early studies have reported that the activation of PPAR $\gamma$ inhibited inflammatory responses, including pro-inflammatory cytokine secretion (188190). These studies also showed that signaling pathways ( $\mathrm{p} 38$, NFKB, ERK1/2) activated via TLR2 and TL4 were inhibited by PPAR $\gamma$ in various condition, such as in T2D, cardiomyopathy, or in MSU crystal-induced acute inflammation in gout, aiding in the resolution of the inflammatory response (191-195) (Figure 5). Later, several studies proved that inflammatory responses highly associated with deficiencies in lipid metabolism are mediated through PPAR $\gamma$.

Regarding inflammasome, an early study using CGI-58 (Comparative Gene Identification-58) deficient mice fed with high-fat diet (HFD) showed that NLRP3 inflammasome was activated in fat, liver, and adipose tissue-derived macrophages (ATMs) through mitochondrial dysfunction and overproduction of ROS, however, importantly, these mechanisms were completely restored by the PPAR $\gamma$ agonist rosiglitazone. CGI-58 is a lipid droplet-associated protein that mediates intracellular fat hydrolysis. Deficiency in this protein leads to the accumulation of cytosolic lipid droplets, hence, limiting the release of FFAs to fuel mitochondrial functions. Consequently, as a result of overnutrition; due to the impaired PPAR $\gamma /$ PGC- 1 signaling axis in the mitochondria, significant mtROS is produced, leading to the activation of NLRP3 inflammasome (196).

Nevertheless, different dietary lipids may mediate inflammatory responses in different ways. A study showed that in contrast to the proinflammatory characteristic $\omega-6$ PUFA, $\omega$-3-PUFA-related compounds (such as 3-(S)-HPOTrE and 13-(S)-HOTrE) significantly inhibited the transcription of NLRP3, caspase-1, IL-1 $\beta$, and IL-18 in LPS-stimulated RAW 264.7 cells and in peritoneal MFs. Interestingly, these effects were reversed when co-incubated with GW9662; a PPAR- $\gamma$ antagonist, indicating that inactivation of inflammasome is mediated through a PPAR $\gamma$-dependent pathway by $\omega$-3-PUFA that functions as a natural agonist of PPAR $\gamma$ (197).

The regulatory role of PPAR $\gamma$ on NLRP3 inflammasome activation was also shown in autoinflammatory diseases. Using a model for hyperuricemia-induced kidney injury, pre-treatment with the PPAR $\gamma$ agonist pioglitazone inhibited the MSU crystalinduced NLRP3 protein expression and IL- $1 \beta$ secretion by HK2 renal tubular cells (198). Later on, an SNP screening of gout patients identified a missense SNP (rs45520937), which causes Arg265Gln (p.R265Q) substitution in the exon 5 of PPARGC1B (PGC-1 $\beta$ ), a transcriptional cofactors of PPAR $\gamma$ (199). PBMCs isolated from gout patients carrying this SNP expressed higher level of NLRP3, and the plasma level showed significantly increased IL-1 $\beta$ cytokine level. Transfecting THP-1 cells with plasmids coding for the PGC- $1 \beta$ SNP allele resulted in highly elevated NLRP3 expression and IL-1 $\beta$ cytokine secretion, compared to the wild type PGC-1 $\beta$ transfected samples (200). These results further support the notion that PPAR $\gamma / \mathrm{PGC}-1$ axis has an important modulatory role in IL-1 $\beta$ production in MSU-induced gouty arthritis.

The capability of PPAR $\gamma$ to inhibit NFKB signaling makes PPAR $\gamma$ a potential modulatory factor in the NLRP3 inflammasome-mediated immune responses. For example, in retinal ganglion cells (glia cells), following retinal ischemia/reperfusion, the expression and activation of NLRP3 inflammasome was inhibited by pioglitazone through the

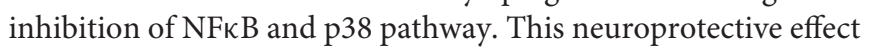
was reversed by the PPAR $\gamma$ antagonist GW9662 $(90,201)$.

Similarly, down-regulation of caspase-1, NLRP3, and IL-1 $\beta$ expression was detected following rosiglitazone treatment in irradiation-induced acute intestinal injury as well as in a spinal cord injury (SCI) model, resulting in anti-inflammatory effects and enhanced locomotor recovery (90).

Essentially, PPAR $\gamma$-mediated NFKB inhibition seems to be an important approach to attenuate inflammatory responses of the intestinal mucosa during colonization with weak pathogens or commensal bacteria. For example, Bacteroides thetaiotaomicron, a gram-negative bacterium and one of the most common bacteria found in human gut flora, induces the association of PPAR $\gamma$ and RelA subunit of NFKB, enhancing its nuclear export through a PPAR $\gamma$-dependent mechanism (202). A similar effect was described in Neisseria lactamica (Nlac); an upper respiratory tract (URT) commensal, showing enhanced PPAR $\gamma$ expression and specifically attenuated TLR1/2 signaling by inhibiting NFKB pathway in nasopharyngeal epithelial cells (203). This way, it provides a protective immunity against pathogenic Neisseria meningitides, which exclusively inhabits the human upper respiratory nasopharyngeal cavity and occasionally causes epidemic meningitis and a rapidly progressing fatal sepsis. However, importantly, in the URT of elderly mice, a significantly high basal expression of TLR1, NLRP3, and IL-1 $\beta$ was detected, and at the same time, significant overexpression of PPAR $\gamma$ was found. Moreover, no further up-regulation of these factors were detected upon colonization, compared to young adult mice where a marked response was developed. This indicates that mediators of tolerance for commensal bacteria are diminished as part of immunosenescence - in part - through PPAR $\gamma$-NFкBNLRP3 pathway. This may explain the increased incidences and susceptibility to respiratory diseases in the elderly (204).

Different subtypes of macrophages have distinct features, mechanisms and dynamics in the secretion of pro-inflammatory cytokines, including IL-1 $\beta$ (205). Furthermore, PPAR $\gamma$ was 


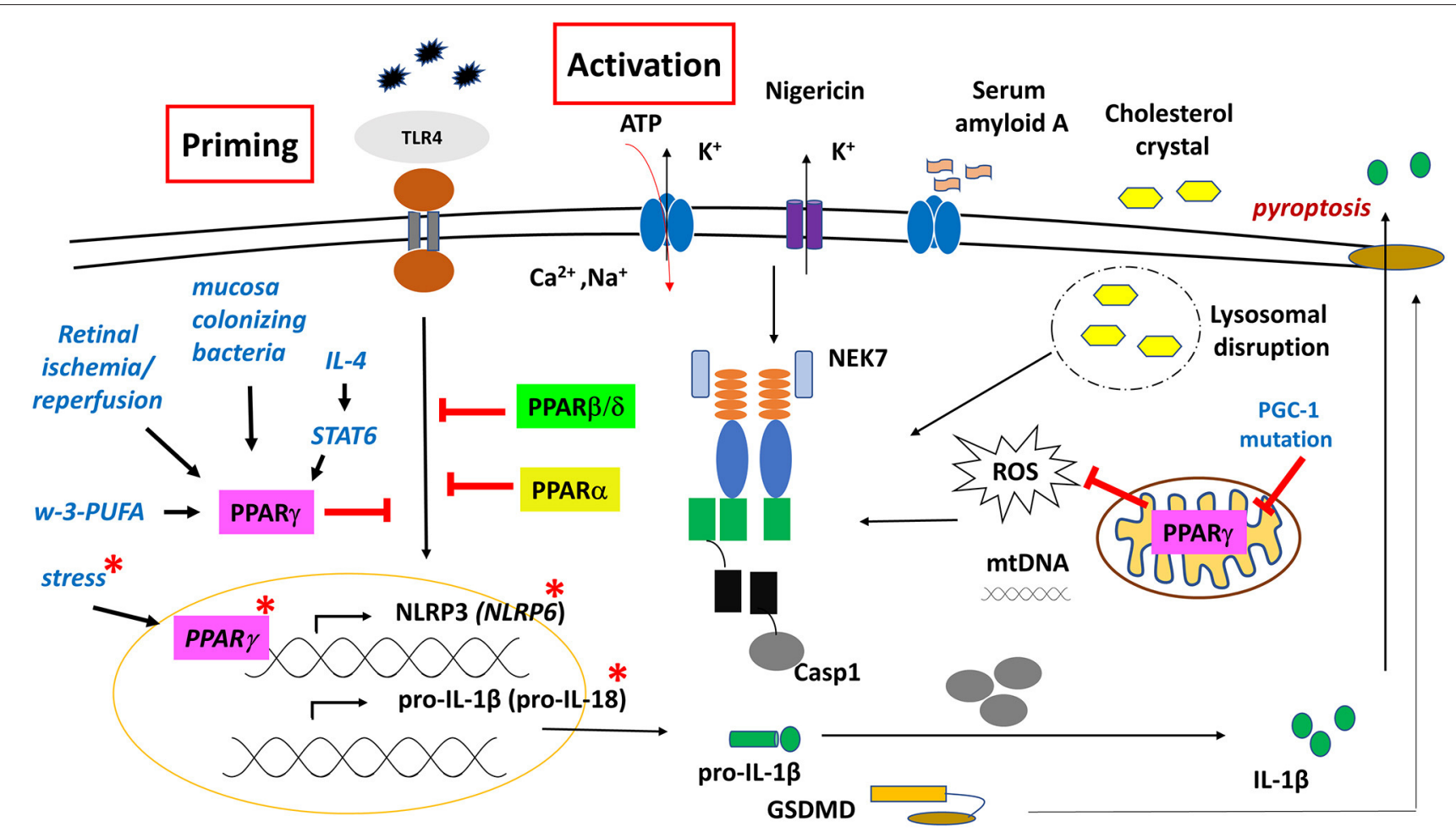

FIGURE 5 | Regulatory role of PPARs on NLRP3 and NLRP6 inflammasome functions. PPAR $\gamma$ has both genomic and non-genomic effects on NLRP3 inflammasome function. Red asterisk indicates molecular events in the gut epithelial cells.

identified as one of the markers of anti-inflammatory macrophages (M2) (206), and a key driver for alternative MFs polarization (207). This notion is further supported by reports showing that the expression of PPAR $\gamma$ (and $\operatorname{PPAR} \beta / \delta$ ) is facilitated by STAT6 transcriptional factor, which is a canonical effector of Th2 signaling, and a regulator of mitochondrial oxidative metabolism to fuel M2's activation (208). Furthermore, we reported that during alternative macrophage polarization, activation of IL-4/STAT-6 signaling axis mediated direct transcriptional repression on LPS-induced inflammatory mediators, including NLRP3 and pro-IL-1 $\beta$ in $\operatorname{BMDM}(209,210)$. These results altogether indicate that PPAR $\gamma$ has a combinatorial/coordinating/conductor role in mediating cell-specific (immune) responses.

\section{PPAR $\gamma$ and NLRP6}

Importantly, studies related to gut homeostasis revealed that not only NLRP3, but also NLRP6 inflammasome is associated with PPAR $\gamma$-mediated regulatory roles as part of the first line of defense in the innate immune responses. The Flavell group reported, for the first time, that a deficiency of NLRP6 inflammasome in mouse colonic epithelial cells resulted in reduced interleukin IL-18 levels and altered fecal microbiota, explaining the increased susceptibility to colonic inflammation (211), and pointing to NLRP6 inflammasome as an important component of the gut's barrier function. Later, transcript profiling of the mucosal epithelia in developing embryos of rat and sheep revealed that components of NLRP6 inflammasome (NLRP6, ASC, caspase-1), and IL-18, were significantly elevated in the developing intestine, but not in the lung (212) (Figure 5). An in silico study of the aligned promoter regions of the human, rat and mouse NLRP6, identified two PPAR $\gamma / R X R$ binding sites in the upstream region that were conserved in the three species. Furthermore, the expression of NLRP6 was highly upregulated in $\mathrm{Caco} 2$ human intestinal epithelial cell line, following PPAR $\gamma$ agonist rosiglitazone treatment. PPAR $\gamma$ is known to be involved in intestinal homeostasis, as administration of rosiglitazone to rodents reduced intestinal colitis, and induced the expression of IL-18 receptor on intraepithelial lymphocytes to induce proliferation in response to IL-18. Given that IL-18 is mainly produced by epithelial cells rather than immune cells in the adult rat and mouse intestine, the NLRP6 inflammasome-mediated IL-18 production probably contributes to the homing of lymphocytes to the intestinal mucosa $(212,213)$.

Under stress (water-avoidance stress) conditions, mice developed enteritis due to inhibition of epithelial NLRP6 expression by the elevated corticotropin-releasing hormone $(\mathrm{CRH})$, while PPAR $\gamma$ agonist rosiglitazone induced NLRP6 expression, and reversed intestinal inflammation (214). Although reports are inconsistent in the intestinal location of NLRP6 expression, studies show that PPAR $\gamma$ activation with its specific agonist has a positive (direct) regulatory effect on NLRP6 expression (215). Furthermore, it highlights the role of 
(intestinal) $\operatorname{PPAR} \gamma$ as an important component of the braingut axis.

\section{$P P A R \beta / \delta$}

$\operatorname{PPAR} \beta / \delta$ is the most ubiquitously expressed of the PPARs. It is activated by a variety of endogenous lipids, including unsaturated fatty acids (FAs), saturated FAs and hydroxyeicosatetraenoic acids. Activation of the receptor induces lipid catabolism through the transcriptional regulation of FA oxidation, mitochondrial biogenesis, and anti-inflammatory response. They also regulate thermogenesis by inducing the expression of UCP in brown adipose tissue and muscle.

Compared to PPAR $\gamma$ and PPAR $\alpha$, the effect of PPAR $\beta / \delta$ on macrophage polarization is controversial, and probably depends on several factors in the microenvironment, the form of the activation, and the origin of the cells. While activation of PPAR $\delta$ did not influence polarization in human macrophages (216), peritoneal macrophages from PPAR $\beta$-deficient mice showed reduced expression of pro-inflammatory genes (217). Nevertheless, in cultured M1 murine MFs, PPAR- $\beta / \delta$ inhibited pro-inflammatory mediators (218), in line with reports showing that synthetic ligands of the receptor exerted anti-inflammatory effects in atherosclerosis, myocardial infarction, acute kidney injury, and lung inflammation (219-221). Furthermore, in murine model of LPS-induced septic shock, PPAR $\beta / \delta$ activation reduced inflammation by inhibiting Akt, STAT3, ERK1/2 and NFkB, iNOS signaling (222).

In association with inflammasomes, Collino et al. described for the first time that in the kidney of high-fructose corn syrup (HFCS-55)-fed mice, increased NLPR3 inflammasome expression, and caspase- 1 activation was markedly reduced by the synthetic PPAR $\delta$ agonist GW0742, which also completely prevented the increase of IL-1 $\beta$ in the serum $(223,224)$. Similarly, in LPS/PA-treated BMDM, PPAR $\beta / \delta$ activation by GW0742 resulted in a suppressed inflammasome activation (225) (Figure 5).

PPAR $\beta / \delta$ was reported as the predominant PPAR subtype in the central nervous system (CNS), and is expressed in all major cell types, including astrocytes, microglia, and neuron (226). While NLRP3 inflammasome-induced neuroinflammation plays a crucial role in dopaminergic neuronal degeneration in Parkinson's disease (PD), agonist treatment of PPARß $/ \delta$ (GW501516) could suppress NLRP3 inflammasome activation in the midbrain of MPTP-induced mouse model of PD. In this study a decreased astrocyte reaction was reported, while the microglia reaction was not affected by the agonist, indicating that the neuroprotective effects of the PPAR $\beta / \delta$ agonist are achieved mainly by targeting astrocytes NLRP3 inflammasome (96).

\section{PPAR $\alpha$}

PPAR $\alpha$ is expressed mainly in higher energy requiring oxidative tissues; such as the skeletal muscle and heart, as well as the liver. PPAR $\alpha$ facilitates mitochondrial FFA import and plays a central role in the control of transport, esterification, and mitochondrial $\beta$-oxidation of fatty acids, by regulating the expression of the related enzymes. PPAR $\alpha$ exerts an important lipid-lowering effect, hence, its down-regulation contributes to heavy lipid accumulation. PPAR $\alpha$ was reported to be activated by natural ligands such as fatty acids and their derivatives, as well as by drugs such as the lipid-lowering fibrates $(227,228)$.

Early reports showed that ligands of PPAR $\alpha$ reduced organ injury and inflammation in animal models of shock (229). It was also reported that secretion of acute phase proteins and inflammatory cytokines was clearly decreased upon activation of PPAR $\alpha$ in various cells; such as liver, endothelial cells or macrophages, likely through the repression of $\mathrm{NF \kappa B}$ pathway (230-233). In line with these findings, PPAR $\alpha / \mathrm{KO}$ mice showed excessive inflammatory response, greater lung tissue damage, and high mortality rate, compare to the wild type, upon intratracheal administration of $P$. aeruginosa. These effects were meditated by hyper-activation of NFKB pathway, and associated with the up-regulation of NLRP3, and expression of caspase-1 and ASC (89) (Figure 5).

Furthermore, the PPAR $\alpha$ agonist fenofibrate, significantly decreased TLR4 and MyD88 expression in a murine model of multiple sclerosis (234), and reversed TXNIP, NLRP3, caspases-1 expression in an in vivo study of STZ-induced diabetic mice. In line with these results, in in vitro studies, fenofibrate treatment significantly inhibited the LPS-induced IL-1 $\beta$ secretion and ROS production in high glucose-treated endothelial progenitor cells (EPCs). These studies suggested that PPAR $\alpha$ may be a good therapeutic candidate to stimulate angiogenesis and accelerate wound healing by deregulating NLRP3 inflammasome activity, and inhibiting IL-1 $\beta$ expression in EPCs of diabetic patients (235).

\section{Vitamin D Receptor (VDR)}

VDR, upon activation by its ligand (1,25-dihydroxyvitamin D), forms a non-permissive heterodimer with RXR, and binds to the vitamin D-response elements (VDREs) to drive the transcriptional of their target genes. VDRs are also targeted by several post-translational modifications that either enhance or suppress their transcriptional activity. VDR is expressed in a wide range of cells, and has cell-type specific functions, that target several biological processes, including mineral homeostasis, immune responses, cell cycle, and apoptosis $(236,237)$.

Vitamin D (or cholecalciferol) can be obtained from the diet, or produced by the epidermis following UVB irradiation, after which it is converted to various physiologically active compounds in different parts of the body. Vitamin $\mathrm{D}$ is first hydroxylated in the liver to form 25-hydroxyvitamin $\mathrm{D}_{3}\left(25-\mathrm{D}_{3}\right)$ or calcidiol; the major circulating vitamin D metabolite in the body. The second hydroxylation occurs mainly in the kidney and peripheral tissues by $1 \alpha$-hydroxylase, to produce the active vitamin $\mathrm{D}$ metabolite 1,25 -dihydroxyvitamin $\mathrm{D}_{3}\left(1,25-\mathrm{D}_{3}\right)$ or calcitriol (238). A clinical research showed that after supplementation with cholecalciferol, high RNA expression of VDR was found in peripheral blood samples (239). Lack of vitamin D or VDR has been linked to a wide spectrum of health conditions, including autoimmune diseases, chronic inflammation, cancer, and high susceptibility to infections $(240,241)$. Vitamin D/VDR axis has also an important role in regulating the oxidative stress [reviewed in (238)], and the adaptive immunity; particularly the development and function of $\mathrm{T}$ cells [extensively reviewed 
in (241)]. $1,25-\mathrm{D}_{3} / \mathrm{VDR}$ signaling mediates the expression of genes involved in antimicrobial responses, including pro-IL$1 \beta$. TLR signaling is reported to transcriptionally regulate the expression of VDR and $1 \alpha$-hydroxylase $(236,237)$. Furthermore, several studies showed that $1,25-\mathrm{D}_{3} / \mathrm{VDR}$ signaling has an important role in the regulation of autophagy through different mechanisms, such as inhibition of the PI3K/Akt/mTOR axis, or modulating the expression of autophagy related genes (e.g., ATG16L1, Beclin-1 and PTPN6) (242-245).

First studies regarding the effect VDR on inflammasome function showed that PMA-differentiated THP-1 cells treated with $25-\mathrm{D}_{3}$ or $1,25-\mathrm{D}_{3}$, exhibited increase in IL- $1 \beta$ release. This effect was abolished by caspase-1- and NLRP3 specific inhibitors. Surprisingly, in this study, reduction in NLRP3 mRNA and protein levels were also detected under exposure to $1,25-$ $\mathrm{D}_{3}(107)$.

Nevertheless, in a murine model, VDR was found to inhibit NLRP3 inflammasome both in vivo and in vitro. VDR-null BMDMs exhibited increase in NLRP3/ASC speck formation in the cytosol. VDR was shown to bind directly to NLRP3 to block BRCC3-mediated NLRP3 deubiquitylation (108) (Figure 4). Notably, licensing of NLRP3 protein through deubiquitylation is a critical step for inflammasome assembly and activation (30). Exposure of BMDMs to 1,25- $\mathrm{D}_{3}$ during LPS/Nigericin treatment resulted in inhibition of IL- $1 \beta$ and caspase-1 cleavage, while $1,25-\mathrm{D}_{3}$ had no effect on IL-1 $\beta$ in VDR-null cells. In vivo, VDR deficient mice showed a decrease in survival rate, compared to the wild type or NLRP3 null mice (108).

In line with these observations, a report showed that in peritoneal macrophages, 1,25- $\mathrm{D}_{3}$-ligated VDR inhibited NLRP3 inflammasome activation induced by various NLRP3 activators (such as ATP, Nig, MSU and alum), and subsequently inhibited caspase- 1 activation and IL- $1 \beta$ secretion; while silencing of VDR abolished those effects. Furthermore, activated VDR inhibited NLRB3 binding to NEK7, and blocked NLRP3mediated ASC oligomerization as well as ROS accumulation, altogether, this disabled the activation of NLRP3 inflammasome. Furthermore, 1,25- $\mathrm{D}_{3}$-promoted polyubiquitination of NLRP3 resulted in the degradation and elimination of the protein through autophagy (106).

Human corneal epithelial cells (hCECs) express a wide range of NLRs (246). In dry eye pathogenesis, hyperosmotic stress (the hallmark of the disease) mediated the activation of ROS-NLRP3-IL-1 $\beta$ signaling axis, leading to inflammation of the corneal epithelial. In vitro, treatment of hCECs with $1,25-\mathrm{D}_{3}$ suppressed hyperosmotic stress-induced cytotoxicity, NLRP3 inflammasome activation, and IL-1 $\beta$ secretion through VDR activation. Silencing of VDR abolished the effects of $1,25-\mathrm{D}_{3}$ on stress-induced IL- $1 \beta$ secretion and cell survival. These effects are attributed to the ability of $1,25-\mathrm{D}_{3}$ to activate NRF2 antioxidant signaling, by lowering ROS generation, and subsequently abrogating NLRP3 inflammasome activation (104).

Administration of $1,25-\mathrm{D}_{3}$ to a mouse model of Porphyromonas gingivalis-induced periodontitis, resulted in the downregulation of NLRP3 inflammasome components in the gingival epithelium. These effects resulted from the ability of $1,25-\mathrm{D}_{3}$ to upregulate the expression of VDR, Aryl hydrocarbon receptor (AhR), and downregulate NF- $\mathrm{kB}$ signaling (109). Although, in macrophages, AhR was reported as a negative regulator of NLRP3 inflammasome, by inhibiting NFkB signaling and NLRP3 transcription (247), in order to verify the direct mechanism of $\mathrm{AhR}$ on inflammasome regulation in the gingival epithelium, additional studies are required. Furthermore, treatment of MRL/lpr mice (a model of SLE) with VDR agonist paricalcitol decreased the pathogenesis of lupus nephritis, through inhibiting NFKB/NLRP3/caspase-1/IL-1 $/ /$ IL18 axis in the renal tissue. Mechanistically, VDR was shown to competitively bind importin 4 and inhibit importin 4-mediated NFKB nuclear translocation (105).

These data suggest that vitamin $\mathrm{D} / \mathrm{VDR}$ axis is an important regulator of inflammasome function. Nevertheless, as VDR transcriptionally regulates more than 900 genes, the results obtained from different sources, or based on VDR deletion studies, should be supported with further detailed studies.

\section{Retinoic Acid Receptor (RAR)}

RARs (RAR $\alpha, \beta, \gamma)$ are ligand dependent transcription factors that function as obligate heterodimers with RXRs. RAR/RXR complex is a non-permissive heterodimer, requiring a ligated RAR partner for activation, while in the absence of ligands, the complex mediates transcriptional repression. As an additional level of regulation, their function can be modulated by various post-translational modifications (PTM). Among several identified retinoic acid derivatives, all-trans retinoic acid (ATRA) is the predominant isoform in the body, and drives the majority of the biological functions of vitamin A (248). Although RAR $\alpha$ has ubiquitous expression, the other isoforms exhibit distinct and tissue-specific expression patterns (249).

Activated RARs may also induce rapid non-transcriptional effects through interaction with several kinase cascades. RARmediated signaling pathways have pleiotropic functions, and are involved in several critical biological processes; such as cell proliferation, differentiation, metabolism, tumorigenesis, hematopoiesis and immune responses $(248,250,251)$. Regarding immune responses, RARs play a central role in modulating the differentiation and function of a spectrum of innate and adaptive immune cells, and any defect in these pathways, or absence of their agonists (e.g., vitamin A deficiency) may be associated with several metabolic and immune disorders [extensively reviewed in $(252-255)]$.

Similar to other nuclear receptors, activation of RAR may lead to various effects, depending on the particular cell, and the microenvironment. ATRA was reported to mediate caspase1 activation in cervical carcinoma cells through IRF-1/STAT1 axis, which suppressed the growth of the cells (256). ATRA has the ability to promote autophagy following intracellular bacterial infection, through interaction with canonical PI3 kinase, Beclin1 , and TBK1 pathway of autophagy (257). Modulation of IL$1 \beta$ secretion by ATRA has been reported for various myeloid, and non-myeloid cells, such as macrophages and mast cells. Studying THP-1 cell line, it was shown that ATRA augmented IL-1 $\beta$ secretion upon Bacillus subtilis flagellin challenge in RAR/RXR-dependent manner. The effect of ATRA on IL-1 $\beta$ secretion was due to the ability of ATRA to enhance the 
$\mathrm{NF} \kappa \mathrm{B}$ pathway (99) (Figure 6). Recently, we reported that ATRA treatment enhanced basal expression of NLRP3 in human monocytes and macrophages. In LPS-activated macrophages, ATRA upregulated the expression of NLRP3 and pro-IL-1 $\beta$, furthermore, it enhanced caspase-1 activation and NLRP3 inflammasome-induced IL-1 $\beta$ secretion. This was attributed to the ability of ATRA to enhance the signal transduction pathways (like NFKB, p38, ERK), and to inhibit AKT/mTOR signaling. Also, it was shown that ATRA enhanced the LPS-induced glycolytic activity of the cells, in part, by inducing hexokinase2 expression, which also participated in the enhanced NLRP3 inflammasome activation (97).

In contrast, in a murine model of alcohol-induced toxicity, an in vivo study showed that ATRA induced the downregulation of NLRP3, pro-caspase- 1 and pro-IL- $1 \beta$ mRNAs in the brain tissue, upon endotoxin treatment. This report demonstrated that while chronic alcohol exposure increased the intestinal permeability for endotoxins, and subsequently elevated the ROS level in the circulation, ATRA developed a protective effect by inhibiting these mechanisms (98).

In mouse intestine epithelial cells, knockdown of RAR $\alpha$ (the most abundant isoform in this cell type) correlated with down-regulation of IL-18, which was associated with the increase in bacterial burden (258). It is suggested that IL-18; produced by intestinal epithelial cells, is responsible for gut homeostasis and $\mathrm{T}$ lymphocyte homing, thus, the link between RAR signaling and inflammasome-mediated IL-18 secretion may warrant further investigation.

\section{REV-ERB and RORs}

Retinoic acid receptor-related orphan receptors (RORs) have several isoforms (ROR $\alpha 1-4, \operatorname{ROR} \beta, \operatorname{ROR} \gamma 1,2$ or $\mathrm{t}$ ), and mainly recognize their response elements as monomers. Expression of these isoforms is controlled by the variable promoter usage and alternative splicing, and exhibits tissue-specificity $(259,260)$. For instance, $\mathrm{ROR} \gamma \mathrm{t}$ is specifically expressed in immune cells, and is considered a key transcription factor for Th17 cell development. Indeed, Th17 cells are implicated in the development of several autoimmune diseases (e.g., autoimmune arthritis), and mice lacking $\operatorname{ROR} \alpha$ and $\operatorname{ROR} \gamma$ exhibit absence of Th17, and are susceptible to developing autoimmune disorders (260-262).

Unlike the other nuclear receptors, REV-ERBs (REV-ERB $\alpha$ and REV-ERB $\beta$ ) bind to their response elements as a monomer or homodimer. REV-ERBs lack the AF2 transactivation domain which is required for binding co-activators and transcriptional activation. Hence, as they recruit the co-repressor ( $\mathrm{NCoR})$ and histone deacetylase 3 (HDAC3) complexes to their target genes, they are considered as transcriptional repressors $(261,263)$. Transcriptionally, REV-ERBs is rhythmically regulated by the core circadian clock complex (BMAL1/CLOCK), and in turn, as part of the feedback loop of the circadian clock genes, REV-ERBs directly represses the transcription of BMAL1. Furthermore, REV-ERBs compete with RORs $(\alpha, \beta, \gamma)$ nuclear receptors (described below) to bind to the promoter of BMAL1, leading to the suppression of ROR-induced BMAL1 expression. Aberrant regulation of either receptors is associated with alteration in the circadian rhythm $(261,264)$.
Indeed, both REV-ERBs and RORs share the same DNA response elements, target genes, and usually co-expressed in the same tissues. Beside the regulation of circadian rhythm, these receptors have also overlapping functions in the regulation of lipid homeostasis, metabolism and immune response (261, 265). However, they identify different ligands, for example heme functions as an endogenous ligand for REV-ERBs, while sterols, oxysterols and cholesterol derivatives act as ligands for RORs. Multifaceted molecular mechanisms of interaction and crosstalk between the circadian clock and immune functions including REV-ERBs and RORs are reviewed elsewhere $(266,267)$. Also, oscillatory expression of NLRP3 inflammasome-related genes or -activity had been reported in several studies $(101,268)$.

Dysregulation in the expression of circadian clock genes including Rev-erb $\alpha$ and Rev-erb $\beta$ has been reported in DSSinduced colitis mouse model. Disruption of circadian clock or deletion of Rev-erb $\alpha$ aggravates colitis conditions, while opposite effects are seen in response to SR9009. Of note, SR9009 was originally designed as an agonist for REV-ERB, however, recently its REV-ERB-independent effects has been also reported (269). Nevertheless, using REV-ERB $\alpha-/-$ mice, increased NLRP3 and IL- $1 \beta$ expression was detected, and REV-ERB $\alpha$ was linked to experimental colitis through its ability to repress the expression of p65 subunit of NFkB, which subsequently leads to the suppression of NLRP3 inflammasome at the priming level (100). However, in experimental colitis, recent report has indicated that NF- $\kappa B$ signaling mediates REV-ERB $\alpha$ expression through LncUC (long non-coding RNA), as a self-healing mechanism to restrain the inflammation (270) (Figure 6).

CHIP analysis of human and mouse macrophages revealed a direct binding of REV-ERB $\alpha$ to the promoters of NLRP3 and IL-1 $\beta$, resulting in a repressed expression. At pathophysiological level REV-ERB $\alpha$ deficient mice displayed increased susceptibility to peritonitis and LPS/D-Galactosamine-induced fulminant hepatitis, whereas activation of REV-ERB $\alpha$ restrained the pathological conditions in an NLRP3 inflammasome-dependent manner (101). However, REV-ERB $\alpha$; expressed in human macrophages, transcriptionally repressed IL-10 expression by recruiting the co-repressor $\mathrm{NCoR}$ and $\mathrm{HDAC} 3$ to its promoter region as part of antimicrobial defense mechanism. Interestingly, in mouse, the REV-ERB $\alpha$ response element motif in IL-10 promoter is disrupted (271).

Similarly, ROR $\gamma$ knock out or ROR $\gamma$ inverse agonists (SR1555, SR2211) diminished NLRP3 inflammasome activation in BMDMs. Indeed, ROR $\gamma$ regulates NLRP3 inflammasome by direct binding to NLRP3 and IL- $1 \beta$ promoters in multiple putative sites. Notably, the same sites were also reported to be recognized by REV-ERB $\alpha$. In vivo, ROR $\gamma$ inverse agonists render protective effects against sepsis and fulminant hepatitis in mouse models mediated by suppression of NLRP3 inflammasome (101, 102). In contrast, dysfunctional $\mathrm{ROR} \alpha\left(\mathrm{ROR} \alpha^{\mathrm{sg} / \mathrm{sg}}\right)$ in septic mice exhibits high levels of NF- $\mathrm{kB}$ signaling, active caspase1 , and IL- $1 \beta$ production (272). In addition, ROR $\alpha$ recruits the corepressor HDAC3 to NF- $\mathrm{kB}$ target promoters, which leads to transcriptional repression of the inflammatory genes (including IL-1 $\beta$ ) in DSS-induced colitis mouse model (273) (Figure 6).

Altogether, given the fact that irregularity in the circadian oscillation is associated with several pathological conditions, 


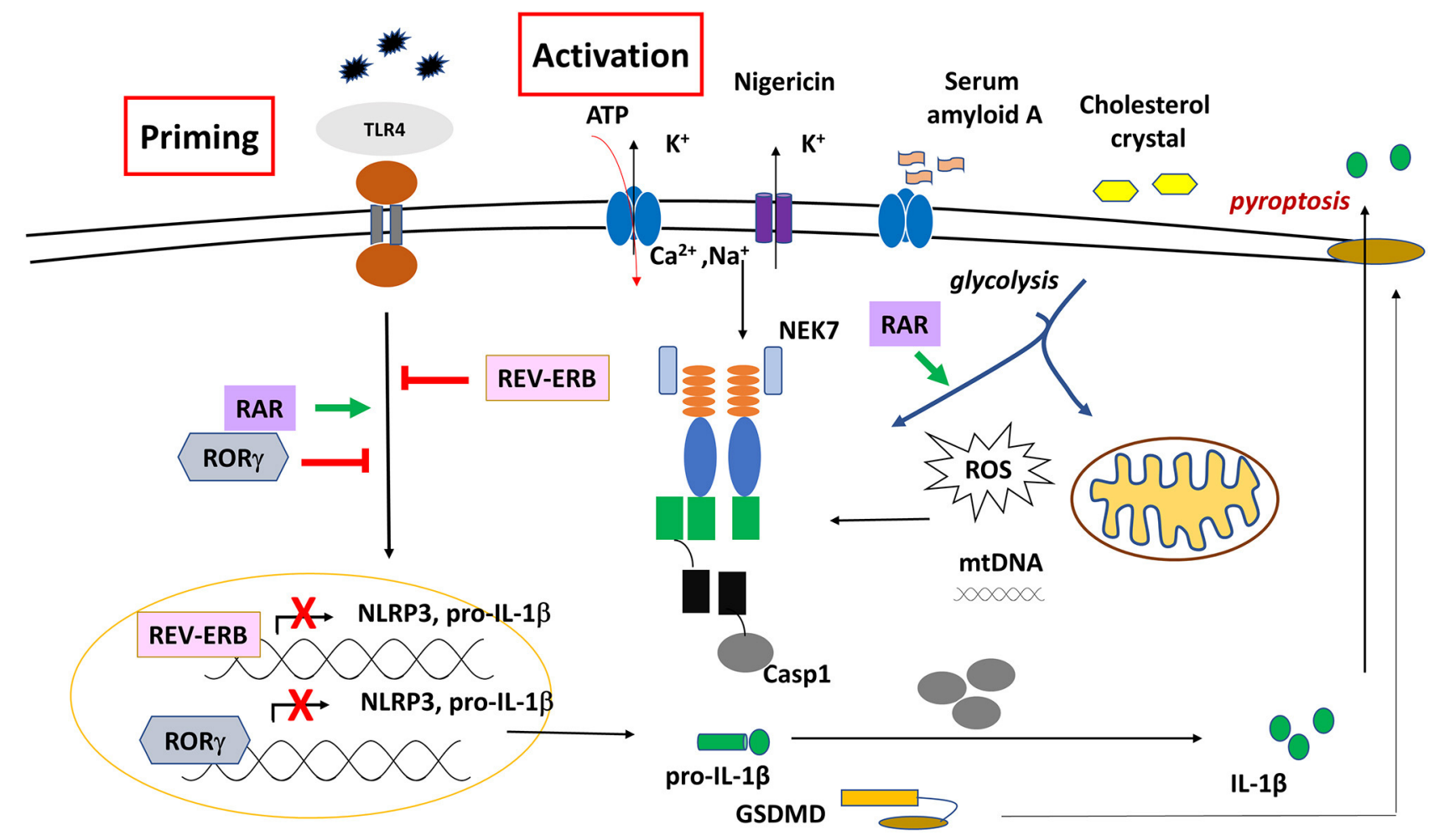

FIGURE 6 | Regulatory role of RAR, REV-ERB, and ROR $\gamma$ on NLRP3 inflammasome functions.

these data suggest an important role for REV-ERBs and RORs in NLRP3 inflammasome regulation, and suggests an association between inflammatory response and circadian rhythm.

\section{CONCLUDING REMARKS AND FUTURE PERSPECTIVES}

This review attempts to draw the attention to nuclear receptors as important modulators of NLRP3 inflammasome function. Nuclear receptors are distributed throughout most tissues and cells, and participate in a wide range of physiological and cellular processes by sensing endogenous or exogenous lipid compounds. Importantly, many of these lipids, their metabolites, or the products of nuclear receptors' target genes can be related directly or indirectly to NLRP3 inflammasome function. Furthermore, NLRP3 is the target of many drug studies as it regulates acute and chronic inflammatory diseases. Although we highlighted a number of mechanisms by which nuclear receptors may regulate the activity of the NLRP3 inflammasome, further detailed studies are required to get a better understanding of the molecular mechanisms that associates the two very complex field. The outcome of nuclear receptors activity in many cases seems to be tissue specific, and dependent on the particular microenvironment and conditions. The fact that nuclear receptors are at the crossroad of metabolism and immune responses, makes them ideal potential targets in therapeutic approaches, where the manipulation of NLRP3 inflammasomemediated cytokine secretion is the aim. However, due to the coordinating role of nuclear receptors in lipid and glucose metabolism, therapeutic usage should be well-designed, and cautiously targeted. Altogether, it requires further investigations to understand the complex cooperation of nuclear receptors with Nod-like receptors, but without doubt, it holds exciting outcomes in the future.

\section{AUTHOR CONTRIBUTIONS}

AA: writing-original draft preparation. SB: writing-original draft preparation, review and editing, supervision. All authors have read and agreed to the published version of the manuscript.

\section{FUNDING}

This work was supported by the Hungarian National Scientific Research Fund (NKFIH-OTKA Grant No. K131844) to SB, and the Faculty of Medicine of the University of Debrecen (1G3DBKD0TUDF 247) to SB. AA holds a Stipendium Hungaricum Scholarship from the Government of Hungary.

\section{ACKNOWLEDGMENTS}

We are very thankful to Dr. Mahdi Mohamed Faisal for the helpful comments and critique. 


\section{REFERENCES}

1. Sonoda J, Pei L, Evans RM. Nuclear receptors: decoding metabolic disease. FEBS Lett. (2008) 582:2-9. doi: 10.1016/j.febslet.2007.11.016

2. Huang P, Chandra V, Rastinejad F. Structural overview of the nuclear receptor superfamily: insights into physiology and therapeutics. Annu Rev Physiol. (2010) 72:247-72. doi: 10.1146/annurev-physiol-021909-135917

3. Liu S, Downes M, Evans RM. Metabolic regulation by nuclear receptors. In: Innovative Medicine. Tokyo: Springer (2015). p. 25-37. doi: 10.1007/978-4-431-55651-0_2

4. Levin ER, Hammes SR. Nuclear receptors outside the nucleus: extranuclear signalling by steroid receptors. Nat Rev Mol cell Biol. (2016) 17:783. doi: $10.1038 / \mathrm{nrm} .2016 .122$

5. Gadaleta RM, Magnani L. Nuclear receptors and chromatin: an inducible couple. J Mol Endocrinol. (2014) 52:R137-49. doi: 10.1530/JME-13-0170

6. Weikum ER, Liu X, Ortlund EA. The nuclear receptor superfamily: a structural perspective. Protein Sci. (2018) 27:1876-92. doi: 10.1002/pro.3496

7. Novac N, Heinzel T. Nuclear receptors: overview and classification. Curr Drug Targets-Inflamm Allergy. (2004) 3:335-46. doi: 10.2174/1568010042634541

8. Benko S, Love JD, Beládi M, Schwabe JWR, Nagy L. Molecular determinants of the balance between co-repressor and co-activator recruitment to the retinoic acid receptor. J Biol Chem. (2003) 278:43797-806. doi: 10.1074/jbc.M306199200

9. Wärnmark A, Treuter E, Wright APH, Gustafsson J-A. Activation functions 1 and 2 of nuclear receptors: molecular strategies for transcriptional activation. Mol Endocrinol. (2003) 17:1901-9. doi: 10.1210/me.2002-0384

10. Sheu S-H, Kaya T, Waxman DJ, Vajda S. Exploring the binding site structure of the PPAR $\gamma$ ligand-binding domain by computational solvent mapping. Biochemistry. (2005) 44:1193-209. doi: 10.1021/bi048032c

11. Anbalagan M, Huderson B, Murphy L, Rowan BG. Post-translational modifications of nuclear receptors and human disease. Nucl Recept Signal. (2012) 10:1-13. doi: 10.1621/nrs.10001

12. Jin L, Li Y. Structural and functional insights into nuclear receptor signaling. Adv Drug Deliv Rev. (2010) 62:1218-26. doi: 10.1016/j.addr.2010.08.007

13. Rastinejad F, Huang P, Chandra V, Khorasanizadeh S. Understanding nuclear receptor form and function using structural biology. J Mol Endocrinol. (2013) 51:T1-21. doi: 10.1530/JME-13-0173

14. Zheng W, Lu Y, Tian S, Ma F, Wei Y, Xu S, et al. Structural insights into the heterodimeric complex of the nuclear receptors FXR and RXR. J Biol Chem. (2018) 293:12535-41. doi: 10.1074/jbc.RA118.004188

15. Love JD, Gooch JT, Benko S, Li C, Nagy L, Chatterjee VKK, et al. The structural basis for the specificity of retinoid-X receptor-selective agonists: new insights into the role of helix H12. J Biol Chem. (2002) 277:11385-91. doi: 10.1074/jbc.M110869200

16. Ordentlich P, Heyman RA. Retinoid Receptors. In: Henry HL, Norman AWBTE, editors. Encyclopedia of Hormones. New York, NY: Academic Press (1994). p. 298-311. doi: 10.1016/B0-12-341103-3/00263-1

17. Annalora AJ, Marcus CB, Iversen PL. Alternative splicing in the nuclear receptor superfamily expands gene function to refine endoxenobiotic metabolism. Drug Metab Dispos. (2020) 48:272-87. doi: $10.1124 / \mathrm{dmd} .119 .089102$

18. De Bosscher $\mathrm{K}$, Desmet SJ, Clarisse D, Estébanez-Perpiña E, Brunsveld L. Nuclear receptor crosstalk-defining the mechanisms for therapeutic innovation. Nat Rev Endocrinol. (2020) 16:1-15. doi: 10.1038/s41574-020-0349-5

19. Xue Y, Tuipulotu DE, Tan WH, Kay C, Man SM. Emerging activators and regulators of inflammasomes and pyroptosis. Trends Immunol. (2019) 40:1035-52. doi: 10.1016/j.it.2019.09.005

20. Liston A, Masters SL. Homeostasis-altering molecular processes as mechanisms of inflammasome activation. Nat Rev Immunol. (2017) 17:20814. doi: 10.1038/nri.2016.151

21. Muñoz-Wolf N, Lavelle EC. Innate immune receptors. In: Di Virgilio F, Pelegrín P, editors. NLR Proteins. Methods in Molecular Biology, Vol. 1417. New York, NY: Humana Press (2016). p. 1-43.

22. Malik A, Kanneganti T-D. Inflammasome activation and assembly at a glance. J Cell Sci. (2017) 130:3955-63. doi: 10.1242/jcs. 207365
23. Guo H, Callaway JB, Ting JPY. Inflammasomes: mechanism of action, role in disease, and therapeutics. Nat Med. (2015) 21:677-87. doi: 10.1038/nm.3893

24. Lim RR, Wieser ME, Ganga RR, Barathi VA, Lakshminarayanan R, Mohan $\mathrm{RR}$, et al. NOD-like receptors in the eye: uncovering its role in diabetic retinopathy. Int J Mol Sci. (2020) 21:1-24. doi: 10.3390/ijms21030899

25. Benko S, Kovács EG, Hezel F, Kufer TA. NLRC5 functions beyond MHC I regulation-what do we know so far? Front Immunol. (2017) 8:150. doi: 10.3389/fimmu.2017.00150

26. Franklin BS, Bossaller L, De Nardo D, Ratter JM, Stutz A, Engels G, et al. The adaptor ASC has extracellular and'prionoid'activities that propagate inflammation. Nat Immunol. (2014) 15:727-37. doi: 10.1038/ni.2913

27. Man SM, Karki R, Kanneganti T. Molecular mechanisms and functions of pyroptosis, inflammatory caspases and inflammasomes in infectious diseases. Immunol Rev. (2017) 277:61-75. doi: 10.1111/imr.12534

28. Ruan J, Xia S, Liu X, Lieberman J, Wu H. Cryo-EM structure of the gasdermin A3 membrane pore. Nature. (2018) 557:62-7. doi: 10.1038/s41586-018-0058-6

29. Cornut M, Bourdonnay E, Henry T. Transcriptional Regulation of Inflammasomes. Int J Mol Sci. (2020) 21:1-28. doi: 10.3390/ijms21218087

30. Song N, Li T. Regulation of NLRP3 inflammasome by phosphorylation. Front Immunol. (2018) 9:2305. doi: 10.3389/fimmu.2018.02305

31. Patel MN, Carroll RG, Galván-Peña S, Mills EL, Olden R, Triantafilou $\mathrm{M}$, et al. Inflammasome priming in sterile inflammatory disease. Trends Mol Med. (2017) 23:165-80. doi: 10.1016/j.molmed.2016. 12.007

32. Shim D-W, Lee K-H. Posttranslational regulation of the NLR family pyrin domain-containing 3 inflammasome. Front Immunol. (2018) 9:1054. doi: 10.3389/fimmu.2018.01054

33. Sharif H, Wang L, Wang WL, Magupalli VG, Andreeva L, Qiao Q, et al. Structural mechanism for NEK7-licensed activation of NLRP3 inflammasome. Nature. (2019) 570:338-43. doi: 10.1038/s41586-019-1295-z

34. Lu A, Magupalli VG, Ruan J, Yin Q, Atianand MK, Vos MR, et al. Unified polymerization mechanism for the assembly of ASC-dependent inflammasomes. Cell. (2014) 156:1193-206. doi: 10.1016/j.cell.2014.02.008

35. Weber ANR, Bittner ZA, Shankar S, Liu X, Chang T-H, Jin T, et al. Recent insights into the regulatory networks of NLRP3 inflammasome activation. $J$ Cell Sci. (2020) 133:1-12. doi: 10.1242/jcs.248344

36. Szekanecz Z, Szamosi S, Kovács GE, Kocsis E, Benko S. The NLRP3 inflammasome-interleukin 1 pathway as a therapeutic target in gout. Arch Biochem Biophys. (2019) 670:82-93. doi: 10.1016/j.abb.2019.01.031

37. Zheng D, Liwinski T, Elinav E. Inflammasome activation and regulation: toward a better understanding of complex mechanisms. Cell Discov. (2020) 6:1-22. doi: 10.1038/s41421-020-0167-x

38. Li W, Cao T, Luo C, Cai J, Zhou X, Xiao X, et al. Crosstalk between ER stress, NLRP3 inflammasome, and inflammation. Appl Microbiol Biotechnol. (2020) 104:1-12. doi: 10.1007/s00253-020-10614-y

39. Meyers AK, Zhu $\mathrm{X}$. The NLRP3 inflammasome: metabolic regulation and contribution to inflammaging. Cells. (2020) 9:1-22. doi: 10.3390/cells9081808

40. Iwasaki Y, Takeshima Y, Fujio K. Basic mechanism of immune system activation by mitochondria. Immunol Med. (2020) 43:1-6. doi: 10.1080/25785826.2020.1756609

41. Yabal M, Calleja DJ, Simpson DS, Lawlor KE. Stressing out the mitochondria: mechanistic insights into NLRP3 inflammasome activation. J Leukoc Biol. (2019) 105:377-99. doi: 10.1002/JLB.MR0318-124R

42. Place DE, Kanneganti T-D. Recent advances in inflammasome biology. Curr Opin Immunol. (2018) 50:32-38. doi: 10.1016/j.coi.2017.10.011

43. Zhou Y, Tong Z, Jiang S, Zheng W, Zhao J, Zhou X. The roles of endoplasmic reticulum in NLRP3 inflammasome activation. Cells. (2020) 9:1-21. doi: 10.3390/cells9051219

44. Heneka MT, McManus RM, Latz E. Inflammasome signalling in brain function and neurodegenerative disease. Nat Rev Neurosci. (2018) 19:610-21. doi: 10.1038/s41583-018-0055-7

45. Mangan MSJ, Olhava EJ, Roush WR, Seidel HM, Glick GD, Latz E. Targeting the NLRP3 inflammasome in inflammatory diseases. Nat Rev Drug Discov. (2018) 17:588-606. doi: 10.1038/nrd.2018.97

46. Nagy L, Szanto A, Szatmari I, Széles L. Nuclear hormone receptors enable macrophages and dendritic cells to sense their lipid environment 
and shape their immune response. Physiol Rev. (2012) 92:739-89. doi: 10.1152/physrev.00004.2011

47. Leopold Wager CM, Arnett E, Schlesinger LS. Macrophage nuclear receptors: emerging key players in infectious diseases. PLoS Pathog. (2019) 15:1-23. doi: 10.1371/journal.ppat.1007585

48. Viola A, Munari F, Sánchez-Rodríguez R, Scolaro T, Castegna A. The metabolic signature of macrophage responses. Front Immunol. (2019) 10:1462. doi: 10.3389/fimmu.2019.01462

49. Nagy ZS, Czimmerer Z, Szanto A, Nagy L. Pro-inflammatory cytokines negatively regulate PPAR $\gamma$ mediated gene expression in both human and murine macrophages via multiple mechanisms. Immunobiology. (2013) 218:1336-44. doi: 10.1016/j.imbio.2013.06.011

50. Heming M, Gran S, Jauch S-L, Fischer-Riepe L, Russo A, Klotz L, et al. Peroxisome proliferator-activated receptor- $\gamma$ modulates the response of macrophages to lipopolysaccharide and glucocorticoids. Front Immunol. (2018) 9:893. doi: 10.3389/fimmu.2018.00893

51. Croasdell A, Duffney PF, Kim N, Lacy SH, Sime PJ, Phipps RP. PPAR $\gamma$ and the innate immune system mediate the resolution of inflammation. PPAR Res. (2015) 2015:1-20. doi: 10.1155/2015/549691

52. Ory DS. Nuclear receptor signaling in the control of cholesterol homeostasis: have the orphans found a home? Circ Res. (2004) 95:660-70. doi: 10.1161/01.RES.0000143422.83209.be

53. Pålsson-McDermott EM, O’Neill LAJ. Targeting immunometabolism as an anti-inflammatory strategy. Cell Res. (2020) 30:300-14. doi: $10.1038 / \mathrm{s} 41422-020-0291-\mathrm{z}$

54. Kawana N, Yamamoto Y, Kino Y, Satoh J. Molecular network of NLRP3 inflammasome activation-responsive genes in a human monocyte cell line. Austin J Clin Immunol. (2014) 1:1-10.

55. Wang L, Nanayakkara G, Yang Q, Tan H, Drummer C, Sun Y, et al. A comprehensive data mining study shows that most nuclear receptors act as newly proposed homeostasis-associated molecular pattern receptors. $J$ Hematol Oncol. (2017) 10:1-41. doi: 10.1186/s13045-017-0526-8

56. Kroemer G, Mariño G, Levine B. Autophagy and the integrated stress response. Mol Cell. (2010) 40:280-93. doi: 10.1016/j.molcel.2010.09.023

57. Chun Y, Kim J. Autophagy: an essential degradation program for cellular homeostasis and life. Cells. (2018) 7:1-26. doi: 10.3390/cells7120278

58. Silwal P, Paik S, Jeon SM, Jo E-K. Nuclear receptors as autophagy-based antimicrobial therapeutics. Cells. (2020) 9:1-24. doi: 10.3390/cells9091979

59. Lee JM, Wagner M, Xiao R, Kim KH, Feng D, Lazar MA, et al. Nutrientsensing nuclear receptors coordinate autophagy. Nature. (2014) 516:112-5. doi: 10.1038/nature13961

60. Sun Q, Fan J, Billiar TR, Scott MJ. Inflammasome and autophagy regulation: a two-way street. Mol Med. (2017) 23:188-95. doi: 10.2119/molmed.2017.00077

61. Biasizzo $M$, Kopitar-Jerala $N$. Interplay between NLRP3 inflammasome and autophagy. Front Immunol. (2020) 11:591803. doi: 10.3389 /fimmu. 2020.591803

62. Unsworth AJ, Flora GD, Gibbins JM. Non-genomic effects of nuclear receptors: insights from the anucleate platelet. Cardiovasc Res. (2018) 114:645-55. doi: $10.1093 / \mathrm{cvr} / \mathrm{cvy} 044$

63. Psarra A-MG, Sekeris CE. Nuclear receptors and other nuclear transcription factors in mitochondria: regulatory molecules in a new environment. Biochim Biophys Acta. (2008) 1783:1-11. doi: 10.1016/j.bbamcr.2007.10.021

64. Reboldi A, Dang EV, McDonald JG, Liang G, Russell DW, Cyster JG. 25-Hydroxycholesterol suppresses interleukin-1-driven inflammation downstream of type I interferon. Science. (2014) 345:679-84. doi: $10.1126 /$ science. 1254790

65. Wen H, Gris D, Lei Y, Jha S, Zhang L, Huang MT-H, et al. Fatty acid-induced NLRP3-ASC inflammasome activation interferes with insulin signaling. Nat Immunol. (2011) 12:408-15. doi: 10.1038/ni.2022

66. Karasawa T, Kawashima A, Usui-Kawanishi F, Watanabe S, Kimura H, Kamata R, et al. Saturated fatty acids undergo intracellular crystallization and activate the NLRP3 inflammasome in macrophages. Arterioscler Thromb Vasc Biol. (2018) 38:744-56. doi: 10.1161/ATVBAHA.117.310581

67. L'homme L, Esser N, Riva L, Scheen A, Paquot N, Piette J, et al. Unsaturated fatty acids prevent activation of NLRP3 inflammasome in human monocytes/macrophages. J Lipid Res. (2013) 54:2998-3008. doi: 10.1194/jlr.M037861
68. Yan Y, Jiang W, Spinetti T, Tardivel A, Castillo R, Bourquin C, et al. Omega-3 fatty acids prevent inflammation and metabolic disorder through inhibition of NLRP3 inflammasome activation. Immunity. (2013) 38:115463. doi: 10.1016/j.immuni.2013.05.015

69. Moon J-S, Nakahira K, Chung K-P, DeNicola GM, Koo MJ, Pabón $\mathrm{MA}$, et al. NOX4-dependent fatty acid oxidation promotes NLRP3 inflammasome activation in macrophages. Nat Med. (2016) 22:1002-12. doi: $10.1038 / \mathrm{nm} .4153$

70. Moon J-S, Lee S, Park M-A, Siempos II, Haslip M, Lee PJ, et al. UCP2induced fatty acid synthase promotes NLRP3 inflammasome activation during sepsis. J Clin Invest. (2015) 125:665-80. doi: 10.1172/JCI78253

71. Joseph SB, Laffitte BA, Patel PH, Watson MA, Matsukuma KE, Walczak R, et al. Direct and indirect mechanisms for regulation of fatty acid synthase gene expression by liver X receptors. J Biol Chem. (2002) 277:11019-25. doi: 10.1074/jbc.M111041200

72. Lu X, Murphy TC, Nanes MS, Hart CM. PPAR $\gamma$ regulates hypoxiainduced Nox4 expression in human pulmonary artery smooth muscle cells through NF-кB. Am J Physiol Cell Mol Physiol. (2010) 299:L559-66. doi: 10.1152/ajplung.00090.2010

73. Nagy L, Tontonoz P, Alvarez JGA, Chen H, Evans RM. Oxidized LDL regulates macrophage gene expression through ligand activation of PPAR $\gamma$. Cell. (1998) 93:229-40. doi: 10.1016/S0092-8674(00)81574-3

74. Song S, Attia RR, Connaughton S, Niesen MI, Ness GC, Elam MB, et al. Peroxisome proliferator activated receptor $\alpha(\operatorname{PPAR} \alpha)$ and PPAR gamma coactivator (PGC-1 $\alpha$ ) induce carnitine palmitoyltransferase IA (CPT-1A) via independent gene elements. Mol Cell Endocrinol. (2010) 325:54-63. doi: 10.1016/j.mce.2010.05.019

75. Sheedy FJ, Grebe A, Rayner KJ, Kalantari P, Ramkhelawon B, Carpenter $\mathrm{SB}$, et al. CD36 coordinates NLRP3 inflammasome activation by facilitating intracellular nucleation of soluble ligands into particulate ligands in sterile inflammation. Nat Immunol. (2013) 14:812-20. doi: 10.1038/ni.2639

76. Westerterp M, Fotakis P, Ouimet M, Bochem AE, Zhang H, Molusky $\mathrm{MM}$, et al. Cholesterol efflux pathways suppress inflammasome activation, NETosis, and atherogenesis. Circulation. (2018) 138:898-912. doi: 10.1161/CIRCULATIONAHA.117.032636

77. Venkateswaran A, Laffitte BA, Joseph SB, Mak PA, Wilpitz DC, Edwards PA, et al. Control of cellular cholesterol efflux by the nuclear oxysterol receptor LXR $\alpha$. Proc Natl Acad Sci USA. (2000) 97:12097-102. doi: 10.1073/pnas.200367697

78. Anand PK. Lipids, inflammasomes, metabolism, and disease. Immunol Rev. (2020) 297:108-22. doi: 10.1111/imr.12891

79. Ralston JC, Lyons CL, Kennedy EB, Kirwan AM, Roche HM. Fatty acids and NLRP3 inflammasome-mediated inflammation in metabolic tissues. Annu Rev Nutr. (2017) 37:77-102. doi: 10.1146/annurev-nutr-071816064836

80. Batista-Gonzalez A, Vidal R, Criollo A, Carreño LJ. New insights on the role of lipid metabolism in the metabolic reprogramming of macrophages. Front Immunol. (2020) 10:2993. doi: 10.3389/fimmu.2019.02993

81. Hao H, Cao L, Jiang C, Che Y, Zhang S, Takahashi S, et al. Farnesoid $\mathrm{X}$ receptor regulation of the NLRP3 inflammasome underlies cholestasis-associated sepsis. Cell Metab. (2017) 25:856-67. doi: 10.1016/j.cmet.2017.03.007

82. Han CY, Rho HS, Kim A, Kim TH, Jang K, Jun DW, et al. FXR inhibits endoplasmic reticulum stress-induced NLRP3 inflammasome in hepatocytes and ameliorates liver injury. Cell Rep. (2018) 24:2985-99. doi: 10.1016/j.celrep.2018.07.068

83. Xie S, Guo C, Chi Z, Huang B, Wu Y, Wang D, et al. A rapid administration of GW 4064 inhibits the NLRP 3 inflammasome activation independent of farnesoid X receptor agonism. FEBS Lett. (2017) 591:283647. doi: 10.1002/1873-3468.12782

84. Sohrabi Y, Sonntag GVH, Braun LC, Lagache SMM, Liebmann M, Klotz L, et al. LXR activation induces a proinflammatory trained innate immunity-phenotype in human monocytes. Front Immunol. (2020) 11:353. doi: 10.3389/fimmu.2020.00353

85. Derangere V, Chevriaux A, Courtaut F, Bruchard M, Berger H, Chalmin $\mathrm{F}$, et al. Liver $\mathrm{X}$ receptor $\beta$ activation induces pyroptosis of human and murine colon cancer cells. Cell Death Differ. (2014) 21:1914-24. doi: $10.1038 /$ cdd.2014.117 
86. Wang S, Lei T, Zhang K, Zhao W, Fang L, Lai B, et al. Xenobiotic pregnane $\mathrm{X}$ receptor (PXR) regulates innate immunity via activation of NLRP3 inflammasome in vascular endothelial cells. J Biol Chem. (2014) 289:30075-81. doi: 10.1074/jbc.M114.578781

87. Hudson G, Flannigan KL, Venu VKP, Alston L, Sandall CF, MacDonald JA, et al. Pregnane $\mathrm{X}$ receptor activation triggers rapid ATP release in primed macrophages that mediates NLRP3 inflammasome activation. J Pharmacol Exp Ther. (2019) 370:44-53. doi: 10.1124/jpet.118.255679

88. Wang S, Xie X, Lei T, Zhang K, Lai B, Zhang Z, et al. Statins attenuate activation of the NLRP3 inflammasome by oxidized LDL or TNF $\alpha$ in vascular endothelial cells through a PXR-dependent mechanism. Mol Pharmacol. (2017) 92:256-64. doi: 10.1124/mol.116.108100

89. Gugliandolo E, Fusco R, Ginestra G, D’amico R, Bisignano C, Mandalari G, et al. Involvement of TLR4 and PPAR- $\alpha$ receptors in host response and NLRP3 inflammasome activation, against pulmonary infection with pseudomonas aeruginosa. Shock. (2019) 51:221-7. doi: 10.1097/SHK.0000000000001137

90. Hu L, Chen H, Zhang X, Feng Z, Zhang H, Meng Q. Rosiglitazone ameliorates radiation-induced intestinal inflammation in rats by inhibiting NLRP3 inflammasome and TNF- $\alpha$ production. J Radiat Res. (2020) 61:84250. doi: $10.1093 / \mathrm{jrr} / \mathrm{rraa} 062$

91. Weber KJ, Sauer M, He L, Tycksen E, Kalugotla G, Razani B, et al. PPAR $\gamma$ deficiency suppresses the release of IL- $1 \beta$ and IL- $1 \alpha$ in macrophages via a type 1 IFN-dependent mechanism. J Immunol. (2018) 201:2054-69. doi: 10.4049/jimmunol.1800224

92. Meng Q-Q, Feng Z-C, Zhang X-L, Hu L-Q, Wang M, Zhang H-F, et al. PPAR- $\gamma$ activation exerts an anti-inflammatory effect by suppressing the nlrp3 inflammasome in spinal cord-derived neurons. Media Inflamm. (2019) 2019:1-12. doi: 10.1155/2019/6386729

93. Meng Q, Lei W, Chen H, Feng Z, Hu L, Zhang X, et al. Combined rosiglitazone and forskolin have neuroprotective effects in SD rats after spinal cord injury. PPAR Res. (2018) 2018:1-11. doi: 10.1155/2018/3897478

94. Yang C-C, Wu C-H, Lin T-C, Cheng Y-N, Chang C-S, Lee K-T, et al. Inhibitory effect of PPAR $\gamma$ on NLRP3 inflammasome activation. Theranostics. (2021) 11:2424-41. doi: 10.7150/thno.46873

95. Lee HJ, Yeon JE, Ko EJ, Yoon EL, Suh SJ, Kang K, et al. Peroxisome proliferator-activated receptor-delta agonist ameliorated inflammasome activation in nonalcoholic fatty liver disease. World J Gastroenterol. (2015) 21:12787-99. doi: 10.3748/wjg.v21.i45.12787

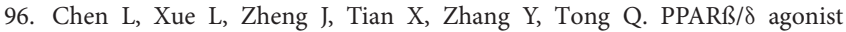
alleviates NLRP3 inflammasome-mediated neuroinflammation in the MPTP mouse model of Parkinson's disease. Behav Brain Res. (2019) 356:483-489. doi: 10.1016/j.bbr.2018.06.005

97. Alatshan A, Kovács GE, Aladdin A, Czimmerer Z, Tar K, Benko S. All-trans retinoic acid enhances both the signaling for priming and the glycolysis for activation of NLRP3 inflammasome in human macrophage. Cells. (2020) 9:1-21. doi: 10.3390/cells9071591

98. Priyanka SH, Thushara AJ, Rauf AA, Indira M. Alcohol induced NLRP3 inflammasome activation in the brain of rats is attenuated by ATRA supplementation. Brain Behav Immunity-Health. (2020) 2:1-5. doi: 10.1016/j.bbih.2019.100024

99. Hoang TX, Jung JH, Kim JY. All-Trans retinoic acid enhances bacterial flagellin-stimulated proinflammatory responses in human monocyte THP1 cells by upregulating CD14. Biomed Res Int. (2019) 2019:1-11. doi: 10.1155/2019/8059312

100. Wang S, Lin Y, Yuan X, Li F, Guo L, Wu B. REV-ERB $\alpha$ integrates colon clock with experimental colitis through regulation of NF- $\kappa$ B/NLRP3 axis. Nat Commun. (2018) 9:1-12. doi: 10.1038/s41467-018-06568-5

101. Pourcet B, Zecchin M, Ferri L, Beauchamp J, Sitaula S, Billon C, et al. Nuclear receptor subfamily 1 group D member 1 regulates circadian activity of NLRP3 inflammasome to reduce the severity of fulminant hepatitis in mice. Gastroenterology. (2018) 154:1449-64. doi: 10.1053/j.gastro.2017. 12.019

102. Billon C, Murray MH, Avdagic A, Burris TP. ROR $\gamma$ regulates the NLRP3 inflammasome. J Biol Chem. (2019) 294:10-19. doi: 10.1074/jbc.AC118.002127

103. Yang C-S, Kim J-J, Kim TS, Lee PY, Kim SY, Lee H-M, et al. Small heterodimer partner interacts with NLRP3 and negatively regulates activation of the NLRP3 inflammasome. Nat Commun. (2015) 6:1-11. doi: $10.1038 /$ ncomms7115

104. Dai Y, Zhang J, Xiang J, Li Y, Wu D, Xu J. Calcitriol inhibits ROS-NLRP3-IL$1 \beta$ signaling axis via activation of $\mathrm{Nrf2}$-antioxidant signaling in hyperosmotic stress stimulated human corneal epithelial cells. Redox Biol. (2019) 21:1-6. doi: 10.1016/j.redox.2018.101093

105. Huang J, Ju B, An Q, Zhang J, Fan P, Hao Z, et al. VDR inhibits NLRP3 signal in lupus nephritis by competitively binding with importin 4 to suppress NF-кB nuclear translocation. (2020) 1-21. doi: 10.21203/rs.3.rs-73578/v1

106. Cao R, Ma Y, Li S, Shen D, Yang S, Wang X, et al. 1, 25 $(\mathrm{OH}) 2 \mathrm{D} 3$ alleviates DSS-induced ulcerative colitis via inhibiting NLRP3 inflammasome activation. J Leukoc Biol. (2020) 108:283-95. doi: 10.1002/JLB.3MA0320-406RR

107. Tulk SE, Liao K, Muruve DA, Li Y, Beck PL, MacDonald JA. Vitamin D3 metabolites enhance the NLRP3-dependent secretion of IL-1 $\beta$ from human THP-1 monocytic cells. J Cell Biochem. (2015) 116:711-20. doi: $10.1002 / j \mathrm{cb} .24985$

108. Rao Z, Chen X, Wu JX, Xiao M, Zhang J, Zhang H, et al. Vitamin D receptor inhibits NLRP3 activation by impeding its deubiquitination mediated by BRCC3. Front Immunol. (2019) 10:1-15. doi: 10.3389/fimmu.2019. 02783

109. Li H, Zhong X, Li W, Wang Q. Effects of 1, 25-dihydroxyvitamin D3 on experimental periodontitis and AhR/NF- $\mathrm{B} / \mathrm{NLRP} 3$ inflammasome pathway in a mouse model. J Appl Oral Sci. (2019) 27:1-10. doi: 10.1590/1678-7757-2018-0713

110. Evans RM, Mangelsdorf DJ. Nuclear receptors, RXR, and the big bang. Cell. (2014) 157:255-66. doi: 10.1016/j.cell.2014.03.012

111. Fadel L, Rehó B, Volkó J, Bojcsuk D, Kolostyák Z, Nagy G, et al. Agonist binding directs dynamic competition among nuclear receptors for heterodimerization with retinoid X receptor. J Biol Chem. (2020) 295:1004561. doi: 10.1074/jbc.RA119.011614

112. Lin YW, Lien LM, Yeh TS, Wu HM, Liu YL, Hsieh RH. 9-cis retinoic acid induces retinoid $\mathrm{X}$ receptor localized to the mitochondria for mediation of mitochondrial transcription. Biochem Biophys Res Commun. (2008) 377:3514. doi: 10.1016/j.bbrc.2008.09.122

113. Roszer T, Menéndez-Gutiérrez MP, Cedenilla M, Ricote M. Retinoid X receptors in macrophage biology. Trends Endocrinol Metab. (2013) 24:460-8. doi: 10.1016/j.tem.2013.04.004

114. Czimmerer Z, Nagy ZS, Nagy G, Horvath A, Silye-Cseh T, Kriston A, et al. Extensive and functional overlap of the STAT6 and RXR cistromes in the active enhancer repertoire of human CD14+ monocyte derived differentiating macrophages. Mol Cell Endocrinol. (2018) 471:63-74. doi: 10.1016/j.mce.2017.07.034

115. Morichika D, Miyahara N, Fujii U, Taniguchi A, Oda N, Senoo S, et al. A retinoid $\mathrm{X}$ receptor partial agonist attenuates pulmonary emphysema and airway inflammation. Respir Res. (2019) 20:1-14. doi: 10.1186/s12931-018-0963-0

116. Lv J, Su W, Yu Q, Zhang M, Di C, Lin X, et al. Heme oxygenase-1 protects airway epithelium against apoptosis by targeting the proinflammatory NLRP3-RXR axis in asthma. J Biol Chem. (2018) 293:18454-65. doi: 10.1074/jbc.RA118.004950

117. Zhang $\mathrm{Y}$, Hagedorn $\mathrm{CH}$, Wang L. Role of nuclear receptor SHP in metabolism and cancer. Biochim Biophys Acta. (2011) 1812:893-908. doi: 10.1016/j.bbadis.2010.10.006

118. Cipriani S, Carino A, Masullo D, Zampella A, Distrutti E, Fiorucci S. Decoding the role of the nuclear receptor SHP in regulating hepatic stellate cells and liver fibrogenesis. Sci Rep. (2017) 7:1-14. doi: 10.1038/srep41055

119. Wang L. Role of small heterodimer partner in lipid homeostasis and its potential as a therapeutic target for obesity. Clin Lipidol. (2010) 2010:445-8. doi: $10.2217 / \mathrm{clp} .10 .44$

120. Yuk JM, Jin HS, Jo EK. Small heterodimer partner and innate immune regulation. Endocrinol Metab. (2016) 31:17-24. doi: 10.3803/EnM.2016.31.1.17

121. Sun S, Kelekar S, Kliewer SA, Mangelsdorf DJ. The orphan nuclear receptor SHP regulates ER stress response by inhibiting XBP1s degradation. Genes Dev. (2019) 33:1083-94. doi: 10.1101/gad.326868.119

122. Ni H, Liu Y, Deng W, Zhang J, Xu J, Zeng W, et al. XBP1 modulates endoplasmic reticulum and mitochondria crosstalk via regulating NLRP3 
inflammasome in renal ischemia/reperfusion injury. Am J Transpl. (2020) 20:717718.

123. Massafra V, van Mil SWC. Farnesoid X receptor: A "homeostat" for hepatic nutrient metabolism. Biochim Biophys Acta. (2018) 1864:45-59. doi: 10.1016/j.bbadis.2017.10.003

124. Massafra V, Ijssennagger N, Plantinga M, Milona A, Pittol JMR, Boes M, et al. Splenic dendritic cell involvement in FXR-mediated amelioration of DSS colitis. Biochim Biophys Acta. (2016) 1862:166-73. doi: 10.1016/j.bbadis.2015.11.001

125. Fiorucci S, Biagioli M, Zampella A, Distrutti E. Bile acids activated receptors regulate innate immunity. Front Immunol. (2018) 9:1853. doi: 10.3389/fimmu.2018.01853

126. Claudel T, Staels B, Kuipers F. The Farnesoid X receptor: a molecular link between bile acid and lipid and glucose metabolism. Arterioscler Thromb Vasc Biol. (2005) 25:2020-30. doi: 10.1161/01.ATV.0000178994.21828.a7

127. Gottlieb A, Canbay A. Why bile acids are so important in nonalcoholic fatty liver disease (NAFLD) progression. Cells. (2019) 8:1-15. doi: $10.3390 /$ cells 8111358

128. Linden AG, Li S, Choi HY, Fang F, Fukasawa M, Uyeda K, et al. Interplay between ChREBP and SREBP-1c coordinates postprandial glycolysis and lipogenesis in livers of mice. J Lipid Res. (2018) 59:475-87. doi: 10.1194/jlr.M081836

129. Chiang JYL, Ferrell JM. Up to date on cholesterol $7 \alpha$-hydroxylase (CYP7A1) in bile acid synthesis. Liver Res. (2020) 4:47-63. doi: 10.1016/j.livres.2020.05.001

130. Szanto A, Benko S, Szatmari I, Balint BL, Furtos I, Rühl R, et al. Transcriptional regulation of human CYP27 integrates retinoid, peroxisome proliferator-activated receptor, and liver $\mathrm{X}$ receptor signaling in macrophages. Mol Cell Biol. (2004) 24:8154-66. doi: $10.1128 / \mathrm{MCB} .24 .18 .8154-8166.2004$

131. Han CY. Update on FXR biology: promising therapeutic target? Int J Mol Sci. (2018) 19:1-25. doi: 10.3390/ijms19072069

132. Shaik FB, Prasad DVR, Narala VR. Role of farnesoid X receptor in inflammation and resolution. Inflamm Res. (2015) 64:9-20. doi: 10.1007/s00011-014-0780-y

133. Francis M, Guo G, Kong B, Abramova E V, Cervelli JA, Gow AJ, et al. Regulation of lung macrophage activation and oxidative stress following ozone exposure by farnesoid X receptor. Toxicol Sci. (2020) 177:441-53. doi: 10.1093/toxsci/kfaa111

134. Pontillo A, Paoluzzi E, Crovella S. The inhibition of mevalonate pathway induces upregulation of NALP3 expression: new insight in the pathogenesis of mevalonate kinase deficiency. Eur J Hum Genet. (2010) 18:844-7. doi: 10.1038/ejhg.2010.9

135. Akula MK, Shi M, Jiang Z, Foster CE, Miao D, Li AS, et al. Control of the innate immune response by the mevalonate pathway. Nat Immunol. (2016) 17:922. doi: 10.1038/ni.3487

136. Wang T, Ma X, Krausz KW, Idle JR, Gonzalez FJ. Role of pregnane X receptor in control of all-trans retinoic acid (ATRA) metabolism and its potential contribution to ATRA resistance. J Pharmacol Exp Ther. (2008) 324:674-84. doi: 10.1124/jpet.107.131045

137. Seok S, Fu T, Choi S-E, Li Y, Zhu R, Kumar S, et al. Transcriptional regulation of autophagy by an FXR-CREB axis. Nature. (2014) 516:108-11. doi: $10.1038 /$ nature 13949

138. Garcia-Irigoyen O, Moschetta A. A novel protective role for FXR against inflammasome activation and endotoxemia. Cell Metab. (2017) 25:763-4. doi: 10.1016/j.cmet.2017.03.014

139. Fang S. Bile acid receptor farnesoid X Receptor: a novel therapeutic target for metabolic diseases. J Lipid Atheroscler. (2017) 6:1-7. doi: 10.12997/jla.2017.6.1.1

140. Schaap FG, Trauner M, Jansen PLM. Bile acid receptors as targets for drug development. Nat Rev Gastroenterol Hepatol. (2014) 11:55. doi: 10.1038/nrgastro.2013.151

141. Mosińska P, Szczepaniak A, Fichna J. Bile acids and FXR in functional gastrointestinal disorders. Dig Liver Dis. (2018) 50:795-803. doi: 10.1016/j.dld.2018.05.016

142. Maroni L, Ninfole E, Pinto C, Benedetti A, Marzioni M. Gut-liver axis and inflammasome activation in cholangiocyte pathophysiology. Cells. (2020) 9:1-13. doi: 10.3390/cells9030736
143. Guo C, Xie S, Chi Z, Zhang J, Liu Y, Zhang L, et al. Bile acids control inflammation and metabolic disorder through inhibition of NLRP3 inflammasome. Immunity. (2016) 45:802-16. doi: 10.1016/j.immuni.2016.09.008

144. Chen X, Guo X, Ge Q, Zhao Y, Mu H, Zhang J. ER stress activates the NLRP3 inflammasome: a novel mechanism of atherosclerosis. Oxid Med Cell Longev. (2019) 2019:1-18. doi: 10.1155/2019/3462530

145. Hegade VS, Speight RA, Etherington RE, Jones DEJ. Novel bile acid therapeutics for the treatment of chronic liver diseases. Therap $A d v$ Gastroenterol. (2016) 9:376-91. doi: 10.1177/1756283X16630712

146. Zhu Z, Zhang Y, Tang Y, Huang S, Chen M, Ju W, et al. Loss of FXR exacerbates liver damage by activating NLRP3 inflammasome induced pyroptosis in liver ischemia reperfusion injury. Transplantation. (2019) 103:279.

147. Jin D, Lu T, Ni M, Wang H, Zhang J, Zhong C, et al. Farnesoid X receptor activation protects liver from ischemia/reperfusion injury by up-regulating small heterodimer partner in kupffer cells. Hepatol Commun. (2020) 4:54054. doi: 10.1002/hep4.1478

148. van de Wiel SMW, Bijsmans ITGW, van Mil SWC, van de Graaf SFJ. Identification of FDA-approved drugs targeting the Farnesoid X Receptor. Sci Rep. (2019) 9:1-11. doi: 10.1038/s41598-019-38668-7

149. Jonker JW, Liddle C, Downes M. FXR and PXR: potential therapeutic targets in cholestasis. J Steroid Biochem Mol Biol. (2012) 130:147-58. doi: 10.1016/j.jsbmb.2011. 06.012

150. Watkins RE, Wisely GB, Moore LB, Collins JL, Lambert MH, Williams $\mathrm{SP}$, et al. The human nuclear xenobiotic receptor PXR: structural determinants of directed promiscuity. Science. (2001) 292:2329-33. doi: $10.1126 /$ science. 1060762

151. Tolson AH, Wang H. Regulation of drug-metabolizing enzymes by xenobiotic receptors: PXR and CAR. Adv Drug Deliv Rev. (2010) 62:1238-49. doi: 10.1016/j.addr.2010.08.006

152. Zhang B, Xie W, Krasowski MD. PXR: a xenobiotic receptor of diverse function implicated in pharmacogenetics. Pharmacogenomics. (2008) 9:1695-709. doi: 10.2217/14622416.9.11.1695

153. Yu Z, Yue B, Ding L, Luo X, Ren Y, Zhang J, et al. Activation of PXR by alpinetin contributes to abrogate chemically induced inflammatory bowel disease. Front Pharmacol. (2020) 11:474. doi: 10.3389/fphar.2020.00474

154. Daujat-Chavanieu M, Gerbal-Chaloin S. Regulation of CAR and PXR expression in health and disease. Cells. (2020) 9:1-40. doi: 10.3390/cells9112395

155. Kodama S, Koike C, Negishi M, Yamamoto Y. Nuclear receptors CAR and PXR cross talk with FOXO1 to regulate genes that encode drugmetabolizing and gluconeogenic enzymes. Mol Cell Biol. (2004) 24:7931-40. doi: 10.1128/MCB.24.18.7931-7940.2004

156. Pascussi J-M, Gerbal-Chaloin S, Duret C, Daujat-Chavanieu M, Vilarem M-J, Maurel P. The tangle of nuclear receptors that controls xenobiotic metabolism and transport: crosstalk and consequences. Annu Rev Pharmacol Toxicol. (2008) 48:1-32. doi: 10.1146/annurev.pharmtox.47.120505.105349

157. Pulakazhi Venu VK, Saifeddine M, Mihara K, Tsai Y-C, Nieves K, Alston L, et al. The pregnane $\mathrm{X}$ receptor and its microbiota-derived ligand indole 3propionic acid regulate endothelium-dependent vasodilation. Am J Physiol Metab. (2019) 317:E350-61. doi: 10.1152/ajpendo.00572.2018

158. Creamer BA, Sloan SNB, Dennis JF, Rogers R, Spencer S, McCuen A, et al. Associations between pregnane $\mathrm{X}$ Receptor and breast cancer growth and progression. Cells. (2020) 9:1-12. doi: 10.3390/cells9102295

159. Xing Y, Yan J, Niu Y. PXR: a center of transcriptional regulation in cancer. Acta Pharm Sin B. (2020) 10:197-206. doi: 10.1016/j.apsb.2019.06.012

160. Kliewer SA, Goodwin B, Willson TM. The nuclear pregnane X receptor: a key regulator of xenobiotic metabolism. Endocr Rev. (2002) 23:687-702. doi: 10.1210/er.2001-0038

161. Chang TKH. Activation of pregnane X receptor (PXR) and constitutive androstane receptor (CAR) by herbal medicines. AAPS J. (2009) 11:590-601. doi: 10.1208/s12248-009-9135-y

162. Sui Y, Meng Z, Park S-H, Lu W, Livelo C, Chen Q, et al. Myeloidspecific deficiency of pregnane $\mathrm{X}$ receptor decreases atherosclerosis in $\mathrm{LDL}$ receptor-deficient mice. J Lipid Res. (2020) 61:696-706. doi: 10.1194/jlr. RA119000122 
163. Yu X, Xu M, Meng X, Li S, Liu Q, Bai M, et al. Nuclear receptor PXR targets AKR1B7 to protect mitochondrial metabolism and renal function in AKI. Sci Transl Med. (2020) 12:1-14. doi: 10.1126/scitranslmed.aay7591

164. Zelcer N, Tontonoz $\mathrm{P}$. Liver $\mathrm{X}$ receptors as integrators of metabolic and inflammatory signaling. J Clin Invest. (2006) 116:607-14. doi: 10.1172/JCI27883

165. Linton MF, Yancey PG, Davies SS, Jerome WG, Linton EF, Song WL, et al. The role of lipids and lipoproteins in atherosclerosis. In: Feingold KR, Anawalt B, Boyce A, Chrousos G, de Herder WW, Dungan K, Grossman A, Hershman JM, Hofland J, Kaltsas G, Koch C, Kopp P, Korbonits M, McLachlan R, Morley JE, New M, Purnell J, Singer F, Stratakis CA, Trence DL, Wilson DP, editors. Endotext. South Dartmouth, MA: MDText.com, Inc. (2000).

166. Moore KJ, Sheedy FJ, Fisher EA. Macrophages in atherosclerosis: a dynamic balance. Nat Rev Immunol. (2013) 13:709-21. doi: 10.1038/nri3520

167. Joseph SB, McKilligin E, Pei L, Watson MA, Collins AR, Laffitte BA, et al. Synthetic LXR ligand inhibits the development of atherosclerosis in mice. Proc Natl Acad Sci. (2002) 99:7604-9. doi: 10.1073/pnas.112059299

168. Wang X, Collins HL, Ranalletta M, Fuki I V, Billheimer JT, Rothblat GH, et al. Macrophage ABCA1 and ABCG1, but not SR-BI, promote macrophage reverse cholesterol transport in vivo. J Clin Invest. (2007) 117:2216-24. doi: 10.1172/JCI32057

169. Ghisletti S, Huang W, Jepsen K, Benner C, Hardiman G, Rosenfeld MG, et al. Cooperative NCoR/SMRT interactions establish a corepressor-based strategy for integration of inflammatory and anti-inflammatory signaling pathways. Genes Dev. (2009) 23:681-93. doi: 10.1101/gad.1773109

170. Ghisletti S, Huang W, Ogawa S, Pascual G, Lin M-E, Willson TM, et al. Parallel SUMOylation-dependent pathways mediate gene-and signalspecific transrepression by LXRs and PPAR $\gamma$. Mol Cell. (2007) 25:57-70. doi: 10.1016/j.molcel.2006.11.022

171. Im S-S, Osborne TF. Liver $x$ receptors in atherosclerosis and inflammation. Circ Res. (2011) 108:996-1001. doi: 10.1161/CIRCRESAHA.110.226878

172. Töröcsik D, Baráth M, Benko S, Széles L, Dezso B, Póliska S, et al. Activation of liver X receptor sensitizes human dendritic cells to inflammatory stimuli. J Immunol. (2010) 184:5456-65. doi: 10.4049/jimmunol.0902399

173. Schulman IG. Liver X receptors link lipid metabolism and inflammation. FEBS Lett. (2017) 591:2978-91. doi: 10.1002/1873-3468.12702

174. Shibata N, Kawarai T, Lee JH, Lee H-S, Shibata E, Sato C, et al. Association studies of cholesterol metabolism genes $(\mathrm{CH} 25 \mathrm{H}, \mathrm{ABCA} 1$ and $\mathrm{CH} 24 \mathrm{H}$ ) in Alzheimer's disease. Neurosci Lett. (2006) 391:142-6. doi: 10.1016/j.neulet.2005.08.048

175. Jang J, Park S, Hur HJ, Cho H-J, Hwang I, Kang YP, et al. 25hydroxycholesterol contributes to cerebral inflammation of X-linked adrenoleukodystrophy through activation of the NLRP3 inflammasome. Nat Commun. (2016) 7:1-11. doi: 10.1038/ncomms13129

176. Li Z, Martin M, Zhang J, Huang H-Y, Bai L, Zhang J, et al. Krüppellike factor 4 regulation of cholesterol-25-hydroxylase and liver $\mathrm{X}$ receptor mitigates atherosclerosis susceptibility. Circulation. (2017) 136:1315-30. doi: 10.1161/CIRCULATIONAHA.117.027462

177. Liao X, Sharma N, Kapadia F, Zhou G, Lu Y, Hong H, et al. Krüppel-like factor 4 regulates macrophage polarization. J Clin Invest. (2011) 121:2736-49. doi: 10.1172/JCI45444

178. Lei C, Lin R, Wang J, Tao L, Fu X, Qiu Y, et al. Amelioration of amyloid $\beta$-induced retinal inflammatory responses by a LXR agonist TO901317 is associated with inhibition of the NF- $\kappa B$ signaling and NLRP3 inflammasome. Neuroscience. (2017) 360:48-60. doi: 10.1016/j.neuroscience.2017.07.053

179. Yu S-X, Chen W, Hu X-Z, Feng S-Y, Li K-Y, Qi S, et al. Liver X receptors agonists suppress NLRP3 inflammasome activation. Cytokine. (2017) 91:3037. doi: $10.1016 /$ j.cyto.2016.12.003

180. Tabraue C, Lara PC, De Mirecki-Garrido M, De La Rosa JV, López-Blanco F, Fernández-Pérez L, et al. LXR signaling regulates macrophage survival and inflammation in response to ionizing radiation. Int J Radiat Oncol Biol Phys. (2019) 104:913-23. doi: 10.1016/j.ijrobp.2019.03.028

181. Pourcet B, Gage MC, León TE, Waddington KE, Pello OM, Steffensen $\mathrm{KR}$, et al. The nuclear receptor LXR modulates interleukin-18 levels in macrophages through multiple mechanisms. Sci Rep. (2016) 6:1-12. doi: $10.1038 /$ srep 25481
182. Hock MB, Kralli A. Transcriptional control of mitochondrial biogenesis and function. Annu Rev Physiol. (2009) 71:177-203. doi: 10.1146/annurev.physiol.010908.163119

183. Christofides A, Konstantinidou E, Jani C, Boussiotis VA. The role of peroxisome proliferator-activated receptors (PPAR) in immune responses. Metabolism. (2020) 114:1-13. doi: 10.1016/j.metabol.2020.154338

184. Szatmari I, Vámosi G, Brazda P, Balint BL, Benko S, Széles L, et al. Peroxisome proliferator-activated receptor $\gamma$-regulated ABCG2 expression confers cytoprotection to human dendritic cells. J Biol Chem. (2006) 281:23812-23. doi: 10.1074/jbc.M604890200

185. Wang Y, Nakajima T, Gonzalez FJ, Tanaka N. PPARs as metabolic regulators in the liver: lessons from liver-specific PPAR-null mice. Int J Mol Sci. (2020) 21:1-15. doi: 10.3390/ijms21062061

186. Bougarne N, Weyers B, Desmet SJ, Deckers J, Ray DW, Staels B, et al. Molecular actions of PPAR $\alpha$ in lipid metabolism and inflammation. Endocr Rev. (2018) 39:760-802. doi: 10.1210/er.2018-00064

187. Zhang L, Chawla A. Role of PPAR $\gamma$ in macrophage biology and atherosclerosis. Trends Endocrinol Metab. (2004) 15:500-5. doi: 10.1016/j.tem.2004.10.006

188. Ricote M, Li AC, Willson TM, Kelly CJ, Glass CK. The peroxisome proliferator-activated receptor- $\gamma$ is a negative regulator of macrophage activation. Nature. (1998) 391:79-82. doi: 10.1038/34178

189. Jiang C, Ting AT, Seed B. PPAR- $\gamma$ agonists inhibit production of monocyte inflammatory cytokines. Nature. (1998) 391:82-6. doi: 10.1038/34184

190. Su CG, Wen X, Bailey ST, Jiang W, Rangwala SM, Keilbaugh SA, et al. A novel therapy for colitis utilizing PPAR- $\gamma$ ligands to inhibit the epithelial inflammatory response. J Clin Invest. (1999) 104:383-9. doi: 10.1172/JCI7145

191. Akahoshi T, Namai R, Murakami Y, Watanabe M, Matsui T, Nishimura A, et al. Rapid induction of peroxisome proliferator-activated receptor $\gamma$ expression in human monocytes by monosodium urate monohydrate crystals. Arthritis Rheum. (2003) 48:231-9. doi: 10.1002/art.10709

192. Akahoshi T, Murakami Y, Kitasato H. Recent advances in crystalinduced acute inflammation. Curr Opin Rheumatol. (2007) 19:146-50. doi: 10.1097/BOR.0b013e328014529a

193. Bai Y-P, Liu Y-H, Chen J, Song T, You Y, Tang Z-Y, et al. Rosiglitazone attenuates NF- $\kappa$ B-dependent ICAM-1 and TNF- $\alpha$ production caused by homocysteine via inhibiting ERK1/2/p38MAPK activation. Biochem Biophys Res Commun. (2007) 360:20-6. doi: 10.1016/j.bbrc.2007.05.222

194. Dasu MR, Park S, Devaraj S, Jialal I. Pioglitazone inhibits Toll-like receptor expression and activity in human monocytes and db/db mice. Endocrinology. (2009) 150:3457-64. doi: 10.1210/en.2008-1757

195. Bae M-A, Song BJ. Critical role of c-Jun N-terminal protein kinase activation in troglitazone-induced apoptosis of human HepG2 hepatoma cells. Mol Pharmacol. (2003) 63:401-8. doi: 10.1124/mol.63.2.401

196. Miao H, Ou J, Ma Y, Guo F, Yang Z, Wiggins M, et al. Macrophage CGI-58 deficiency activates ROS-inflammasome pathway to promote insulin resistance in mice. Cell Rep. (2014) 7:223-35. doi: 10.1016/j.celrep.2014.02.047

197. Kumar N, Gupta G, Anilkumar K, Fatima N, Karnati R, Reddy GV, et al. 15-Lipoxygenase metabolites of $\alpha$-linolenic acid,[13-(S)-HPOTrE and 13-(S)-HOTrE], mediate anti-inflammatory effects by inactivating NLRP3 inflammasome. Sci Rep. (2016) 6:1-14. doi: 10.1038/srep31649

198. Hong W, Hu S, Zou J, Xiao J, Zhang X, Fu C, et al. Peroxisome proliferatoractivated receptor $\gamma$ prevents the production of NOD-like receptor family, pyrin domain containing 3 inflammasome and interleukin $1 \beta$ in HK-2 renal tubular epithelial cells stimulated by monosodium urate crystals. $\mathrm{Mol} \mathrm{Med}$ Rep. (2015) 12:6221-6. doi: 10.3892/mmr.2015.4145

199. Finck BN, Kelly DP. PGC-1 coactivators: inducible regulators of energy metabolism in health and disease. J Clin Invest. (2006) 116:615-22. doi: 10.1172/JCI27794

200. Chang W-C, Jan Wu Y-J, Chung W-H, Lee Y-S, Chin S-W, Chen T-J, et al. Genetic variants of PPAR-gamma coactivator 1B augment NLRP3mediated inflammation in gouty arthritis. Rheumatology. (2017) 56:457-66. doi: 10.1093/rheumatology/kew337

201. Zhang Y-L, Wang R-B, Li W-Y, Xia F-Z, Liu L. Pioglitazone ameliorates retinal ischemia/reperfusion injury via suppressing NLRP3 inflammasome activities. Int J Ophthalmol. (2017) 10:1812-8. doi: 10.18240/ijo.2017. 12.04 
202. Kelly D, Campbell JI, King TP, Grant G, Jansson EA, Coutts AGP, et al. Commensal anaerobic gut bacteria attenuate inflammation by regulating nuclear-cytoplasmic shuttling of PPAR- $\gamma$ and RelA. Nat Immunol. (2004) 5:104-12. doi: 10.1038/ni1018

203. Tezera LB, Hampton J, Jackson SK, Davenport V. Neisseria lactamica attenuates TLR-1/2-induced cytokine responses in nasopharyngeal epithelial cells using PPAR- $\gamma$. Cell Microbiol. (2011) 13:554-68. doi: 10.1111/j.1462-5822.2010.01554.x

204. Krone CL, Trzciński K, Zborowski T, Sanders EAM, Bogaert D. Impaired innate mucosal immunity in aged mice permits prolonged Streptococcus pneumoniae colonization. Infect Immun. (2013) 81:4615-25. doi: 10.1128/IAI.00618-13

205. Budai MM, Tozsér J, Benko S. Different dynamics of NLRP3 inflammasome-mediated IL-1 $\beta$ production in GM-CSF-and M-CSFdifferentiated human macrophages. J Leukoc Biol. (2017) 101:1335-47. doi: 10.1189/jlb.3A0716-300RR

206. Bouhlel MA, Derudas B, Rigamonti E, Dièvart R, Brozek J, Haulon S, et al. PPAR $\gamma$ activation primes human monocytes into alternative M2 macrophages with anti-inflammatory properties. Cell Metab. (2007) 6:13743. doi: 10.1016/j.cmet.2007.06.010

207. Odegaard JI, Ricardo-Gonzalez RR, Goforth MH, Morel CR, Subramanian $\mathrm{V}$, Mukundan L, et al. Macrophage-specific PPAR $\gamma$ controls alternative activation and improves insulin resistance. Nature. (2007) 447:1116-20. doi: $10.1038 /$ nature 05894

208. Brestoff JR, Artis D. Immune regulation of metabolic homeostasis in health and disease. Cell. (2015) 161:146-60. doi: 10.1016/j.cell.2015.02.022

209. Czimmerer Z, Daniel B, Horvath A, Rückerl D, Nagy G, Kiss M, et al. The transcription factor STAT6 mediates direct repression of inflammatory enhancers and limits activation of alternatively polarized macrophages. Immunity. (2018) 48:75-90. doi: 10.1016/j.immuni.2017.12.010

210. Daniel B, Nagy G, Horvath A, Czimmerer Z, Cuaranta-Monroy I, Poliska $\mathrm{S}$, et al. The IL-4/STAT6/PPAR $\gamma$ signaling axis is driving the expansion of the RXR heterodimer cistrome, providing complex ligand responsiveness in macrophages. Nucleic Acids Res. (2018) 46:4425-39. doi: 10.1093/nar/gky157

211. Elinav E, Strowig T, Kau AL, Henao-Mejia J, Thaiss CA, Booth CJ, et al. NLRP6 inflammasome regulates colonic microbial ecology and risk for colitis. Cell. (2011) 145:745-57. doi: 10.1016/j.cell.2011.04.022

212. Kempster SL, Belteki G, Forhead AJ, Fowden AL, Catalano RD, Lam BY, et al. Developmental control of the Nlrp6 inflammasome and a substrate, IL-18, in mammalian intestine. Am J Physiol Liver Physiol. (2011) 300:G253-63. doi: 10.1152/ajpgi.00397.2010

213. Hasan AU, Rahman A, Kobori H. Interactions between host PPARs and gut microbiota in health and disease. Int J Mol Sci. (2019) 20:1-19. doi: 10.3390/ijms20020387

214. Sun Y, Zhang M, Chen C, Gillilland III M, Sun X, El-Zaatari M, et al. Stressinduced corticotropin-releasing hormone-mediated NLRP6 inflammasome inhibition and transmissible enteritis in mice. Gastroenterology. (2013) 144:1478-87. doi: 10.1053/j.gastro.2013.02.038

215. Ranson N, Veldhuis M, Mitchell B, Fanning S, Cook AL, Kunde D, et al. Nod-like receptor pyrin-containing protein 6 (NLRP6) is up-regulated in ileal Crohn's disease and differentially expressed in goblet cells. Cell Mol Gastroenterol Hepatol. (2018) 6:110-2. doi: 10.1016/j.jcmgh.2018.03.001

216. Bouhlel MA, Brozek J, Derudas B, Zawadzki C, Jude B, Staels B, et al. Unlike PPAR $\gamma, \operatorname{PPAR} \alpha$ or $\operatorname{PPAR} \beta / \delta$ activation does not promote human monocyte differentiation toward alternative macrophages. Biochem Biophys Res Commun. (2009) 386:459-62. doi: 10.1016/j.bbrc.2009.06.047

217. Lee C-H, Chawla A, Urbiztondo N, Liao D, Boisvert WA, Evans RM. Transcriptional repression of atherogenic inflammation: modulation by PPAR $\delta$. Science. (2003) 302:453-7. doi: 10.1126/science.1087344

218. Welch JS, Ricote M, Akiyama TE, Gonzalez FJ, Glass CK. PPARgamma and PPARdelta negatively regulate specific subsets of lipopolysaccharide and IFN-gamma target genes in macrophages. Proc Natl Acad Sci USA. (2003) 100:6712-7. doi: 10.1073/pnas.1031789100

219. Letavernier E, Perez J, Joye E, Bellocq A, Fouqueray B, Haymann J-P, et al. Peroxisome proliferator-activated receptor $\beta / \delta$ exerts a strong protection from ischemic acute renal failure. J Am Soc Nephrol. (2005) 16:2395-402. doi: 10.1681/ASN.2004090802
220. Haskova Z, Hoang B, Luo G, Morgan LA, Billin AN, Barone FC, et al. Modulation of LPS-induced pulmonary neutrophil infiltration and cytokine production by the selective PPAR $\beta / \delta$ ligand GW0742. Inflamm Res. (2008) 57:314-21. doi: 10.1007/s00011-007-7157-4

221. Rodríguez-Calvo R, Serrano L, Coll T, Moullan N, Sánchez RM, Merlos M, et al. Activation of peroxisome proliferator-activated receptor $\beta / \delta$ inhibits lipopolysaccharide-induced cytokine production in adipocytes by lowering nuclear factor- $\kappa \mathrm{B}$ activity via extracellular signal-related kinase $1 / 2$. Diabetes. (2008) 57:2149-57. doi: 10.2337/db08-0176

222. Kapoor A, Shintani Y, Collino M, Osuchowski MF, Busch D, Patel NSA, et al. Protective role of peroxisome proliferator-activated receptor$\beta / \delta$ in septic shock. Am J Respir Crit Care Med. (2010) 182:1506-15. doi: 10.1164/rccm.201002-0240OC

223. Collino M, Benetti E, Rogazzo M, Mastrocola R, Yaqoob MM, Aragno M, et al. Reversal of the deleterious effects of chronic dietary HFCS-55 intake by PPAR- $\delta$ agonism correlates with impaired NLRP3 inflammasome activation. Biochem Pharmacol. (2013) 85:257-64. doi: 10.1016/j.bcp.2012.10.014

224. Fuentes-Antrás J, Ioan AM, Tunon J, Egido J, Lorenzo O. Activation of toll-like receptors and inflammasome complexes in the diabetic cardiomyopathy-associated inflammation. Int J Endocrinol. (2014) 2014:111. doi: $10.1155 / 2014 / 847827$

225. Dai L, Bhargava P, Stanya KJ, Alexander RK, Liou Y-H, Jacobi D, et al. Macrophage alternative activation confers protection against lipotoxicity-induced cell death. Mol Metab. (2017) 6:1186-97. doi: 10.1016/j.molmet.2017.08.001

226. Warden A, Truitt J, Merriman M, Ponomareva O, Jameson K, Ferguson LB, et al. Localization of PPAR isotypes in the adult mouse and human brain. Sci Rep. (2016) 6:27618. doi: 10.1038/srep27618

227. Han L, Shen W-J, Bittner S, Kraemer FB, Azhar S. PPARs: regulators of metabolism and as therapeutic targets in cardiovascular disease. Part II: PPAR- $\beta / \delta$ and PPAR- $\gamma$. Future Cardiol. (2017) 13:279-96. doi: 10.2217/fca-2017-0019

228. Phua WWT, Wong MXY, Liao Z, Tan NS. An aPPARent functional consequence in skeletal muscle physiology via peroxisome proliferatoractivated receptors. Int J Mol Sci. (2018) 19:1-28. doi: 10.3390/ijms19051425

229. Di Paola R, Esposito E, Mazzon E, Genovese T, Muià C, Crisafulli C, et al. Absence of peroxisome proliferators-activated receptors (PPAR) $\alpha$ enhanced the multiple organ failure induced by zymosan. Shock. (2006) 26:477-84. doi: 10.1097/00024382-200610001-00076

230. Staels B, Koenig W, Habib A, Merval R, Lebret M, Torra IP, et al. Activation of human aortic smooth-muscle cells is inhibited by PPAR $\alpha$ but not by PPAR $\gamma$ activators. Nature. (1998) 393:790-3. doi: 10.1038/31701

231. Madej A, Okopien B, Kowalski J, Zielinski M, Wysocki J, Szygula B, et al. Effects of fenofibrate on plasma cytokine concentrations in patients with atherosclerosis and hyperlipoproteinemia IIb. Int J Clin Pharmacol Ther. (1998) 36:345-9.

232. Chinetti G, Griglio S, Antonucci M, Torra IP, Delerive P, Majd Z, et al. Activation of proliferator-activated receptors $\alpha$ and $\gamma$ induces apoptosis of human monocyte-derived macrophages. J Biol Chem. (1998) 273:25573-80. doi: $10.1074 /$ jbc.273.40.25573

233. Zandbergen F, Plutzky J. PPAR $\alpha$ in atherosclerosis and inflammation. Biochim Biophys Acta. (2007) 1771:972-82. doi: 10.1016/j.bbalip.2007.04.021

234. Xu J, Racke MK, Drew PD. Peroxisome proliferator-activated receptor$\alpha$ agonist fenofibrate regulates IL-12 family cytokine expression in the CNS: relevance to multiple sclerosis. J Neurochem. (2007) 103:1801-10. doi: 10.1111/j.1471-4159.2007.04875.x

235. Deng Y, Han X, Yao Z, Sun Y, Yu J, Cai J, et al. PPAR $\alpha$ agonist stimulated angiogenesis by improving endothelial precursor cell function via a NLRP3 inflammasome pathway. Cell Physiol Biochem. (2017) 42:2255-66. doi: 10.1159/000479999

236. Pike JW, Meyer MB, Lee S-M, Onal M, Benkusky NA. The vitamin D receptor: contemporary genomic approaches reveal new basic and translational insights. J Clin Invest. (2017) 127:1146-54. doi: 10.1172/JCI88887

237. Khammissa RAG, Fourie J, Motswaledi MH, Ballyram R, Lemmer J, Feller L. The biological activities of vitamin $\mathrm{D}$ and its receptor in relation to calcium and bone homeostasis, cancer, immune and cardiovascular 
systems, skin biology, and oral health. Biomed Res Int. (2018) 2018:1-10. doi: 10.1155/2018/9276380

238. Kim D-H, Meza CA, Clarke H, Kim J-S, Hickner RC. Vitamin D and endothelial function. Nutrients. (2020) 12:1-17. doi: 10.3390/nu12020575

239. Medeiros JFP, de Oliveira Borges MV, Soares AA, Dos Santos JC, de Oliveira $\mathrm{ABB}$, da Costa CHB, et al. The impact of vitamin D supplementation on VDR gene expression and body composition in monozygotic twins: randomized controlled trial. Sci Rep. (2020) 10:1-10. doi: 10.1038/s41598-020-69128-2

240. Mora JR, Iwata M, Von Andrian UH. Vitamin effects on the immune system: vitamins A and D take centre stage. Nat Rev Immunol. (2008) 8:685-98. doi: $10.1038 /$ nri2378

241. Kongsbak M, Levring TB, Geisler C, Von Essen MR. The vitamin $\mathrm{D}$ receptor and $\mathrm{T}$ cell function. Front Immunol. (2013) 4:1-10. doi: $10.3389 /$ fimmu.2013.00148

242. Kumar S, Nanduri R, Bhagyaraj E, Kalra R, Ahuja N, Chacko AP, et al. Vitamin D3-VDR-PTPN6 axis mediated autophagy contributes to the inhibition of macrophage foam cell formation. Autophagy. (2020) 2020:1-17. doi: 10.1080/15548627.2020.1822088

243. Tavera-Mendoza LE, Westerling T, Libby E, Marusyk A, Cato L, Cassani $\mathrm{R}$, et al. Vitamin D receptor regulates autophagy in the normal mammary gland and in luminal breast cancer cells. Proc Natl Acad Sci USA. (2017) 114:E2186-94. doi: 10.1073/pnas.1615015114

244. Lu R, Zhang Y, Xia Y, Sun J. Imbalance of autophagy and apoptosis in intestinal epithelium lacking the vitamin D receptor. FASEB J. (2019) 33:11845-56. doi: 10.1096/fj.201900727R

245. Suares A, Tapia C, González-Pardo V. VDR agonists down regulate PI3K/Akt/mTOR axis and trigger autophagy in Kaposi's sarcoma cells. Heliyon. (2019) 5:1-13. doi: 10.1016/j.heliyon.2019.e02367

246. Benko S, Tozser J, Miklossy G, Varga A, Kadas J, Csutak A, et al. Constitutive and UV-B modulated transcription of Nod-like receptors and their functional partners in human corneal epithelial cells. Mol Vis. (2008) 14:1575-83. Available online at: http://www.molvis.org/molvis/v14/ a187/

247. Huai W, Zhao R, Song H, Zhao J, Zhang L, Zhang L, et al. Aryl hydrocarbon receptor negatively regulates NLRP3 inflammasome activity by inhibiting NLRP3 transcription. Nat Commun. (2014) 5:1-9. doi: 10.1038/ncomms5738

248. Conserva MR, Anelli L, Zagaria A, Specchia G, Albano F. The pleiotropic role of retinoic acid/retinoic acid receptors signaling: from vitamin a metabolism to gene rearrangements in acute promyelocytic leukemia. Int J Mol Sci. (2019) 20:1-22. doi: 10.3390/ijms20122921

249. Duong V, Rochette-Egly C. The molecular physiology of nuclear retinoic acid receptors. From health to disease. Biochim Biophys Acta. (2011) 1812:102331. doi: 10.1016/j.bbadis.2010.10.007

250. di Martino O, Welch JS. Retinoic acid receptors in acute myeloid leukemia therapy. Cancers. (2019) 11:1-14. doi: 10.3390/cancers11121915

251. Al Tanoury Z, Piskunov A, Rochette-Egly C. Vitamin a and retinoid signaling: genomic and nongenomic effects thematic review series: fat-soluble vitamins: Vitamin a. J Lipid Res. (2013) 54:1761-75. doi: 10.1194/jlr.R030833

252. Pino-Lagos K, Guo Y, Noelle RJ. Retinoic acid: a key player in immunity. Biofactors. (2010) 36:430-6. doi: 10.1002/biof.117

253. Oliveira L de M, Teixeira FME, Sato MN. Impact of retinoic acid on immune cells and inflammatory diseases. Mediators Inflamm. (2018) 2018:1-17. doi: 10.1155/2018/3067126

254. Larange A, Cheroutre H. Retinoic acid and retinoic acid receptors as pleiotropic modulators of the immune system. Annu Rev Immunol. (2016) 34:369-94. doi: 10.1146/annurev-immunol-041015-055427

255. Huang Z, Liu Y, Qi G, Brand D, Zheng SG. Role of vitamin A in the immune system. J Clin Med. (2018) 7:1-16. doi: 10.3390/jcm7090258

256. Arany I, Ember IA, Tyring SK. All-trans-retinoic acid activates caspase-1 in a dose-dependent manner in cervical squamous carcinoma cells. Anticancer Res. (2003) 23:471-3.

257. Coleman MM, Basdeo SA, Coleman AM, Cheallaigh CN, Peral de Castro C, McLaughlin AM, et al. All-trans retinoic acid augments autophagy during intracellular bacterial infection. Am J Respir Cell Mol Biol. (2018) 59:548-56. doi: $10.1165 / \mathrm{rcmb} .2017-0382 \mathrm{OC}$

258. Iyer N, Grizotte-Lake M, Duncan K, Gordon SR, Palmer ACS, Calvin $\mathrm{C}$, et al. Epithelium intrinsic vitamin A signaling co-ordinates pathogen clearance in the gut via IL-18. PLoS Pathog. (2020) 16:e1008360. doi: 10.1371/journal.ppat.1008360

259. Kamenecka TM, Lyda B, Chang MR, Griffin PR. Synthetic modulators of the retinoic acid receptor-related orphan receptors. Medchemcomm. (2013) 4:764-76. doi: $10.1039 / \mathrm{c} 3 \mathrm{md} 00005 \mathrm{~b}$

260. Rutz S, Eidenschenk C, Kiefer JR, Ouyang W. Post-translational regulation of ROR $\gamma$ t-A therapeutic target for the modulation of interleukin-17-mediated responses in autoimmune diseases. Cytokine Growth Factor Rev. (2016) 30:1-17. doi: 10.1016/j.cytogfr.2016.07.004

261. Kojetin DJ, Burris TP. REV-ERB and ROR nuclear receptors as drug targets. Nat Rev Drug Discov. (2014) 13:197-216. doi: 10.1038/nrd4100

262. Park J-S, Moon S-J, Lim M, Byun J-K, Hwang S-H, Yang S, et al. Retinoic acid receptor-related receptor alpha ameliorates autoimmune arthritis via inhibiting of Th17 cells and osteoclastogenesis. Front Immunol. (2019) 10:2270. doi: 10.3389/fimmu.2019.02270

263. Feng D, Liu T, Sun Z, Bugge A, Mullican SE, Alenghat T, et al. A circadian rhythm orchestrated by histone deacetylase 3 controls hepatic lipid metabolism. Science. (2011) 331:1315-9. doi: 10.1126/science.1198125

264. Takahashi JS. Transcriptional architecture of the mammalian circadian clock. Nat Rev Genet. (2017) 18:164-79. doi: 10.1038/nrg.2016.150

265. Solt LA, Kojetin DJ, Burris TP. The REV-ERBs and RORs: molecular links between circadian rhythms and lipid homeostasis. Future Med Chem. (2011) 3:623-38. doi: 10.4155/fmc.11.9

266. Hergenhan S, Holtkamp S, Scheiermann C. Molecular interactions between components of the circadian clock and the immune system. J Mol Biol. (2020) 432:3700-13. doi: 10.1016/j.jmb.2019.12.044

267. Carter SJ, Durrington HJ, Gibbs JE, Blaikley J, Loudon AS, Ray DW, et al. A matter of time: study of circadian clocks and their role in inflammation. $J$ Leukoc Biol. (2016) 99:549-60. doi: 10.1189/jlb.3RU1015-451R

268. Pourcet B, Duez H. Circadian control of inflammasome pathways: implications for circadian medicine. Front Immunol. (2020) 11:1-13. doi: 10.3389/fimmu.2020.01630

269. Dierickx P, Emmett MJ, Jiang C, Uehara K, Liu M, Adlanmerini M, et al. SR9009 has REV-ERB-independent effects on cell proliferation and metabolism. Proc Natl Acad Sci USA. (2019) 116:12147-52. doi: 10.1073/pnas.1904226116

270. Wang S, Lin Y, Li F, Qin Z, Zhou Z, Gao L, et al. An NF-кB-driven lncRNA orchestrates colitis and circadian clock. Sci Adv. (2020) 6:1-12. doi: 10.1126/sciadv.abb5202

271. Chandra V, Mahajan S, Saini A, Dkhar HK, Nanduri R, Raj EB, et al. Human IL10 gene repression by Rev-erb $\alpha$ ameliorates Mycobacterium tuberculosis clearance. J Biol Chem. (2013) 288:10692-702. doi: 10.1074/jbc.M113.455915

272. García JA, Volt H, Venegas C, Doerrier C, Escames G, López LC, et al. Disruption of the NF-kB/NLRP3 connection by melatonin requires retinoidrelated orphan receptor- $\alpha$ and blocks the septic response in mice. FASEB J. (2015) 29:3863-75. doi: 10.1096/fj.15-273656

273. Oh SK, Kim D, Kim K, Boo K, Yu YS, Kim IS, et al. ROR $\alpha$ is crucial for attenuated inflammatory response to maintain intestinal homeostasis. Proc Natl Acad Sci USA. (2019) 116:21140-21149. doi: 10.1073/pnas.1907595116

Conflict of Interest: The authors declare that the research was conducted in the absence of any commercial or financial relationships that could be construed as a potential conflict of interest.

Copyright $\odot 2021$ Alatshan and Benkö. This is an open-access article distributed under the terms of the Creative Commons Attribution License (CC BY). The use, distribution or reproduction in other forums is permitted, provided the original author(s) and the copyright owner(s) are credited and that the original publication in this journal is cited, in accordance with accepted academic practice. No use distribution or reproduction is permitted which does not comply with these terms. 